\title{
金属有机框架基复合材料的制备及其光热性能研究
}

\author{
郭彩霞尔杰* 王博* \\ (北京理工大学 化学与化工学院 北京 100081)
}

\begin{abstract}
摘要 金属有机框架材料(metal-organic frameworks, MOFs)是一类新型的有机-无机杂化材料, 具有可功能化的骨架结 构、高比表面积、可调控的孔径尺寸等优势. 将 MOFs 与性质多样的有机/无机功能纳米材料复合, 不仅有可能充分发 挥组分各自的优势, 而且有可能产生 “ $1+1>2$ ” 的协同效应, 因而引起了人们的广泛关注. 具有光热效应的 MOF 复 合物作为一类重要的 MOF复合材料, 在生物诊疗、催化等领域展现出了良好的应用前景. 作者首先综述了近年来 MOF 复合材料的主要可控制备方法, 随后讨论了光热 MOF 复合材料的应用研究, 最后对该类材料的未来研究方向和挑战 进行了展望.
\end{abstract}

关键词 金属有机骨架材料; 复合材料; 光热效应; 肿瘤治疗; 协同催化

\section{Metal-organic Frameworks-based Composites and Their Photothermal Applications}

\author{
Caixia Guo Xiaojie Ma* Bo Wang* \\ (School of Chemistry and Chemical Engineering, Beijing Institute of Technology, Beijing 100081, China)
}

\begin{abstract}
Metal-organic frameworks (MOFs) are a growing class of organic-inorganic hybrid crystalline porous materials, showing high levels of structural and chemical diversity. They have a wide range of applications in gas adsorption and separation, catalysis, sensing, biomedicine and other fields. Due to their intriguing properties such as high porosity, adjustable pore size and tunable surface functionality, MOFs have been gaining popularity as a promising platform for integration of various organic/inorganic functional nanomaterials in a predictable and controllable way. The combination of MOFs and functional components offers a possibility to generate synergetic effect between functional units, thus leading to the creation of multifunctional materials with performance superior to each individual components. In this review, we summarized recent research progress on controllable synthesis of MOF composites. There are basically two strategies, including "bottle in ship" and "ship in bottle". Following that, preparation methods including solution infiltration, deposition, solid grinding and template synthesis, were discussed in detail. Light-to-heat conversion materials have always been a research focus due to their important applications in solar powered water evaporation and near-infrared (NIR) excited bioimaging and noninvasive cancer treatment. MOFs can not only show intrinsic structure-dependent photoresponse activity, but also serve as porous supports to facilitate the stabilization and spatial distribution of photothermal nanoparticles. Recently, MOF composites with photothermal effects have aroused increasing attention in the fields like tumor diagnosis and treatment, bacterial disinfection and synergistic catalysis. This review mainly focused on the recent research progress on photothermal MOF composites. We discussed the integration of functional MOFs with various inorganic/organic photothermal nanoparticles (e.g. Au, Pt, porphyrin, polydopamine etc.), along with the structure and photothermal application of the composites. Research about MOFs based light-to-heat conversion is at the stage of rapid development. Finally, we also give a prospect to the future development of multifunctional and photothermal MOF composites.
\end{abstract}

Keywords metal-organic framework; composite material; photothermal effect; tumor treatment; synergistic catalysis

\section{1 引言}

金属有机框架材料 (metal-organic frameworks, $\mathrm{MOF}$ ) 是一类由过渡金属离子或金属簇与含氧、氮等多 齿有机配体通过配位键自组装形成的结构高度有序的 超分子配位晶态多孔聚合物 ${ }^{[1-2]}$. MOFs 作为一种新兴的
晶态多孔材料，因可实现在原子、分子尺度上对其组成、 结构以及物理化学性质的可控设计和调节, 不论在基础 研究还是应用研究领域都受到了学者的高度关注. 近年 来, 国内外许多研究团队致力于 MOFs 的功能设计、可 控合成、材料的构效关系探究 ${ }^{[3-6]}$, 并对其在气体存储与

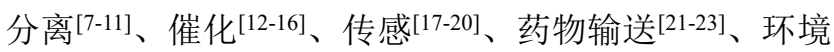

\footnotetext{
*E-mail: xiaojiema@bit.edu.cn; bowang@bit.edu.cn

Received April 22, 2021; published May 25, 2021.

Project supported by the National Natural Science Foundation of China (Nos. 21625102, 21801017, 21490570, 21674012), Beijing Municipal Science and Technology Project (Z181100004418001), and Beijing Institute of Technology Research Fund Program.

项目受国家自然科学基金(Nos. 21625102, 21801017, 21490570, 21674012)、北京市科委科技计划项目(No. Z181100004418001)和北京理工大学科研基 金项目资助。
} 
污染物控制[24-27]、生物医药 ${ }^{[28-30]}$ 等领域的潜在应用进行 了深入探索，在材料开发和相应的应用领域做出了许多 杰出的贡献. 目前, 已有数以万计种 MOFs 被报道. 同 时, 伴随着简易、低成本的 MOFs 合成方法的逐渐涌现 以及 MOFs 应用研究探索的深入, MOFs 已成为最具现 代化工业应用前景的化学材料之一. 然而, MOFs 自身 也存在一些不足. 例如, 在结构稳定性方面, MOFs 相较 于活性炭、沸石、分子篮等传统多孔材料普遍较差; 在 催化方面, 高本征活性的 MOFs 因其配体结构大多都较 为复杂, 功能化 MOFs 在设计和合成方面很大程度上依 赖于研究团队的实践经验以及大量的实验篮选工作, 耗 时耗力. 近年来, MOF 复合物受到了越来越多研究者的 重视. 面向具体应用, 通过原位合成或合成后处理等多 种策略, 将具有明确功能且活性优异的组分, 可控地引 入到稳定性较好且孔道结构和化学环境均满足要求的 MOFs 中, 所形成的复合物不仅有可能实现多组分各自 优势的结合, 而且可以产生 “ $1+1>2$ ” 的协同效应, 并 最终改善 MOFs 和功能组分各自在材料合成、稳定性或 者活性方面存在的不足.

光热性能是指材料将吸收的光转化为热的性质. 目 前已报道的具有光热性能的材料主要包括四类, 分别是 贵金属纳米颗粒(如金、银等纳米粒子 [31-32])、金属半导 体纳米颗粒(如纳米硫化铜、纳米硫化钼等 ${ }^{[33]}$ )、碳基纳 米材料(如石墨烯、碳量子点等 ${ }^{[34-36]}$ )以及聚合物(如聚多 巴胺、聚苯胺等 ${ }^{[37-38]}$ ). 通常, 材料主要通过如下三种机 制产生光热效应(如图 1 所示): (1)通过吸收光能引起表 面局域等离子体共振将光能转化为电子或空穴谐振的 动能, 从而引起环境温度的升高; (2)通过吸收光引起电 子跃迁, 在电子无辐射弛豫回到基态的过程中, 释放热 量; (3)通过吸收光后引起分子的振动, 产生热.
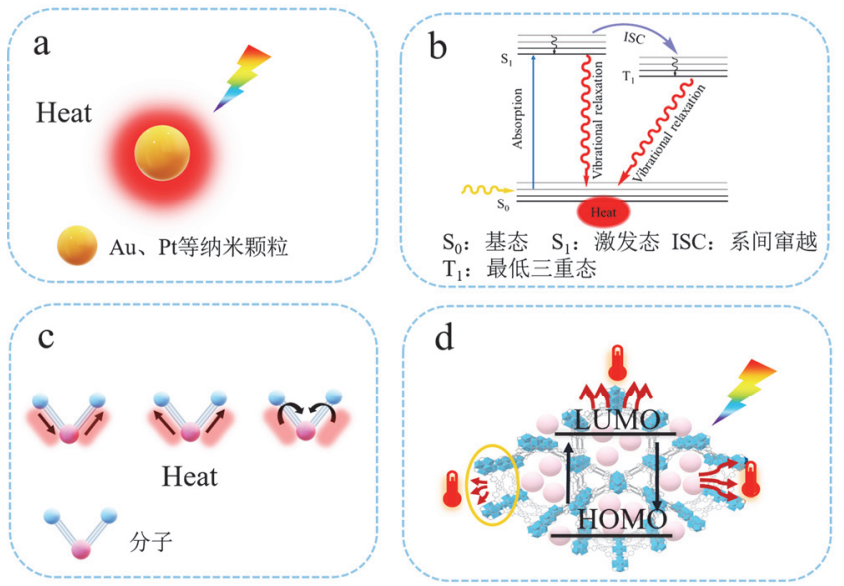

图 $1 \quad(\mathrm{a} \sim \mathrm{c})$ 光热机制示意图; (d) 光热 $\mathrm{MOF}$ 复合物示意图

Figure $1 \quad(a \sim c)$ Schematic illustration of photothermal mechanisms; (d) schematic illustration of the photothermal MOF composites

光热材料由于可以利用具有较强生物组织穿透能 力的近红外光或者太阳能这一储量丰富的清洁能源, 在 生物诊疗、海水淡化、污染物降解等领域展现出了重要
价值. MOF 基复合材料在光热应用方面的主要优势如 下：(1)复合材料有助于拓宽单一材料对光谱的利用范 围; (2) MOFs 作为载体材料, 不仅可以实现对光热材料 粒径、分散程度和位置等的有效控制，而且可以提高某 些光热材料的光热稳定性; (3) 光热纳米颗粒在多孔 MOFs 中呈均匀分散状态, 这有助于光引发的热向环境 高效传递; (4)可通过 MOF 材料, 实现光热纳米颗粒与 其他功能材料(如光催化纳米颗粒)的有序组装, 充分发 挥光热与其他作用的协同效应.

本综述首先总结了 $\mathrm{MOF}$ 基复合材料的制备策略和 方法, 进而着重讨论了 $\mathrm{MOF}$ 复合物用于光热肿瘤治疗、 光热杀菌、光热协同催化等相关领域的研究进展(图 2), 最后对上述领域所面临的挑战及未来的发展进行了展 望.

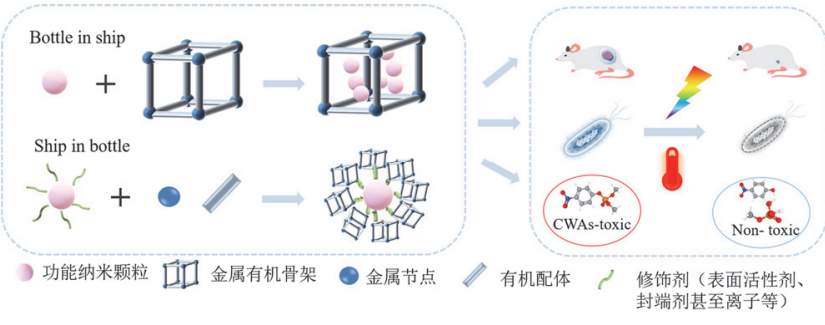

图 $2 \mathrm{MOF}$ 复合材料制备策略及光热应用(光热肿瘤治疗、光热杀菌 及光热协同催化领域)示意图

Figure 2 Schematic illustration of synthetic strategies and photothermal applications (photothermal tumor treatment, photothermal-disinfection, photothermal synergistic catalysis) for MOF composites

\section{MOF 复合材料的制备}

纳米颗粒与 MOFs 的复合主要有两种策略: (1)通过 在预先合成的 MOF 孔道内生长纳米颗粒(即 “船中造 瓶”); (2)将预先合成的纳米粒子置于 MOFs 的前驱体溶 液中, 进而实现在 MOFs 生长过程中对纳米粒子的成功 封装(即“瓶外造船”). 第一种策略有助于实现小尺寸、 均匀、活性位点充分暴露的纳米粒子或族在 MOF 孔道 内的可控分散，但该策略对 MOF 的孔道大小有较高的 要求. 对于第二种策略, 通常需要使用一些表面活性 剂、封端剂或离子来稳定预合成的纳米颗粒，并且由于 合成的纳米颗粒的流体动力学半径远大于 MOF 空腔尺 寸, 所以纳米颗粒不占据 $\mathrm{MOF}$ 孔道, 而是被在其周围 生长的 MOFs 所包围, 但该方法中表面活性剂的使用可 能会造成活性催化位点的不完全暴露 ${ }^{[39]}$. 基于上述策 略, 目前主要有包括溶液浸渍法、沉积法、固体研磨法 以及模板合成法在内的四种 MOF 复合材料合成方法(图 3). 基于 MOFs 的复合方法与技术一直是领域内的研究 热点和重点. 如何利用简便、易操作的方法批量对 MOFs 与功能纳米颗粒进行复合, 并实现活性组分形 貌、尺寸、位置、分散性等的高度可控, 是 MOF 复合 材料制备面临的重要挑战之一. 


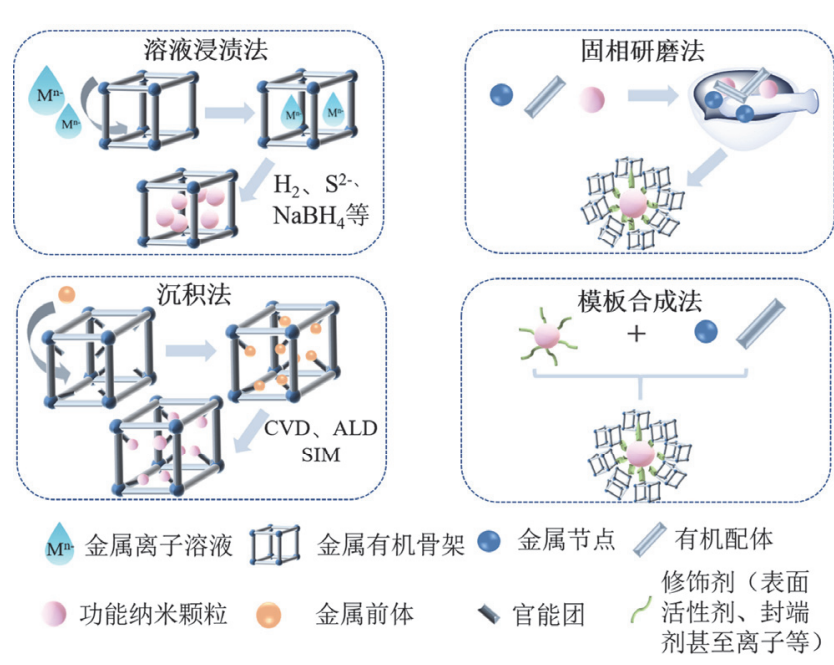

图 $3 \mathrm{MOF}$ 复合材料的合成方法示意图

Figure 3 Schematic illustration of synthetic methods for MOF composites

\section{1 溶液浸渍法}

该方法主要采用 “瓶中造船” 策略. 通过将真空活 化后的 MOF 材料浸泡在一定量的金属盐前体溶液中, 进而利用毛细作用使前驱体渗透到 MOF 孔隙中, 最后 用 $\mathrm{H}_{2}$ 或 $\mathrm{NaBH}_{4}$ 等还原剂对其进行还原, 以实现金属纳 米颗粒在 MOF 孔道中的封装. 通过对前驱体进行硫化 处理，也可实现 MOF 孔道中金属硫化物的原位封装 ${ }^{[40]}$.

Kaskel 及其合作者 ${ }^{[41]}$ 以 $\left[\mathrm{Pd}(\mathrm{acac})_{2}\right](\mathrm{acac}=$ 乙酰丙 酮)为前驱体, 通过湿润浸渍的方法, 将含有 $\mathrm{Pd}(\mathrm{acac})_{2}$ 的氯仿溶液缓慢滴加至真空活化后的 MOF-5 $\left(\mathrm{Zn}_{4} \mathrm{O}(\mathrm{bdc})_{3}, \mathrm{bdc}=1,4-\right.$ 对苯二甲酸)粉末中, 通过 $\mathrm{H}_{2}$ 的还 原处理得到了 $\mathrm{Pd} / \mathrm{MOF}-5$ 复合材料, 通过 $\mathrm{X}$ 射线粉末衍 射(XRD)及 $77 \mathrm{~K}$ 下的 $\mathrm{N}_{2}$ 吸附等表征证明了该复合材料 的成功制备. Kapteijn 及其合作者 ${ }^{[42]}$ 通过湿法浸渍将氯 铂酸引入 MIL-101 中, 然后在甲醛溶液中进行超声处 理, 实现了氯铂酸的初步还原, 最后在空气中分多个阶 段进行干燥处理得到了 Pt-MIL-101(Cr). 利用 XRD、X 射线光电子能谱、扫描透射电子显微镜(STEM)、傅立 叶变换红外光谱(FT-IR)等表征手段, 证明了 $4 \mathrm{~nm}$ 左右 的 Pt 纳米颗粒在 MIL-101(Cr)孔隙内的成功封装.

黄文裕及其合作者 ${ }^{[43]}$ 以具有较小空腔的 UiO-66- $\mathrm{NH}_{2}$ 为模板和载体, 在浸渍过程中通过改变铂 前驱体与 MOFs 之间的比例来调节 Pt 的含量, 获得了在 MOF 空腔内限域生长的 Pt NCs. 段镶锋及其合作者 ${ }^{[44]}$ 的研究表明, 溶剂的选择在控制前驱体负载和 MOF 孔 道内还原速率以形成纳米线方面起着重要作用. 通过改 变溶剂体系(即还原环境), 获得了在 MOF-545 中限域生 长的高密度、超薄、排列整齐的金纳米线、铂纳米线. 具 有高比表面积、丰富催化活性位点的 MOF-545 与等离 激元金纳米线或高活性铂纳米线结合, 使复合材料具有 应用于协同催化领域的潜力.

通过溶液浸渍的方法, 研究人员也成功合成了多金
属负载的 MOF 复合材料. 2011 年, 徐强课题组 ${ }^{[45]}$ 首次 提出通过顺序沉积还原法, 将具有核一壳结构的双金属 NPs 沉积到多孔 MOFs 上. 其将去溶剂化的 ZIF-8 依次 浸入 $\mathrm{Au}$ 和 $\mathrm{Ag}$ 前体的水溶液中, 分别通过方法 $\mathrm{I}$ 还原和 干燥, 得到 $\mathrm{Au} @ \mathrm{Ag}$ 核壳 NPs; 通过方法 II, 按照 $\mathrm{Ag}$ 和 $\mathrm{Au}$ 的相反沉积顺序制备了 $\mathrm{Au} @ \mathrm{AuAg} \mathrm{NPs}$ (图 4). 与单 金属和合金 NPs 相比, 双金属 Au@Ag NPs 的协同作用 提高了复合材料的催化活性.

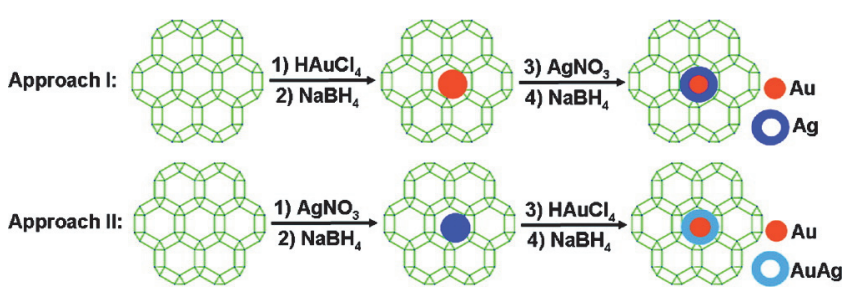

图 4 制备方法示意图. 改编自文献[45]

Figure 4 Schematic illustration for the preparation methods. Adapted from the literature [45]

罗威及其合作者 ${ }^{[46]}$ 通过溶液浸渍法将具有不同物 质的量比的 $\mathrm{NiCl}_{2}$ 和 $\mathrm{K}_{2} \mathrm{PtCl}_{6}$ 引入 MIL-101 中, 利用嗍氢 化钠还原, 获得了具有不同比例的 $\mathrm{Ni} / \mathrm{Pt}$ 组成的 NiPt@MIL-101 催化剂. 王春及其合作者 ${ }^{[47]}$ 通过调节 $\mathrm{Ag} / \mathrm{Pd}$ 前驱体的物质的量比, 合成了一系列 $\mathrm{Ag}_{x} \mathrm{Pd}_{y} @$ UiO-66- $\mathrm{NH}_{2}$ 复合催化剂, 其中 $\mathrm{Ag}_{1} \mathrm{Pd}_{4} @ \mathrm{UiO}-66-\mathrm{NH}_{2}$ 对 氨硼烷的催化水解表现出最高的催化活性.

为了增强金属前体与 MOFs 间的强相互作用，最大 程度减少纳米颗粒在 MOF 表面的附着及形成分散更为 均匀的纳米颗粒, 研究人员利用 MOF 金属簇上配位不 饱和的金属位点(CUSs) 实现了纳米颗粒在 MOF 孔道中 的原位生长. Ferey 课题组 ${ }^{[48]}$ 通过将乙二胺(ED)配位至 脱水的 MIL-101 骨架上来合成 ED 功能化的 MIL-101 (ED-MIL-101), 然后用 $\mathrm{HCl}$ 水溶液中和表面胺基, 带正 电荷的表面铵基与阴离子贵金属盐即 $\left[\mathrm{PtCl}_{4}\right]^{2-}$ 、 $\left[\mathrm{PtCl}_{6}\right]^{2-} 、\left[\mathrm{AuCl}_{4}\right]^{2-}$ 反应，最后在低温下用 $\mathrm{NaBH}_{4}$ 缓慢 还原贵金属，通过 XRD、 $\mathrm{N}_{2}$ 吸附等表征证明了金属纳 米颗粒在 MOF 孔道中负载.

通过溶液浸渍法, 研究人员也实现了金属氧化物和 金属硫化物与 MOFs 的复合. 邓鹤翔及其合作者 ${ }^{[49}$ 通过 将 $\mathrm{MOF}$ ( 分别为 MIL-101-Cr、MIL-101-Cr- $\mathrm{NO}_{2}$ 、 MIL-101-Cr-NH $\mathrm{N}_{2} 、 \mathrm{MIL}-101-\mathrm{Al}-\mathrm{NH}_{2}$ 和 MIL-101-Fe)与钛 前体溶液混合, 在 $18{ }^{\circ} \mathrm{C}$ 摚拌 $20 \mathrm{~h}$. 然后将混合物中的 溶剂在室温下蒸发, 最后在 $80{ }^{\circ} \mathrm{C}$ 的沙浴中老化 $1 \mathrm{~h}$, 在 此期间，钛前体逐步水解直至完全脱水. 通过 XRD、三 维(3D)电子密度图、3D 电子衍射断层扫描(3D EDT)、 高角度环形暗场扫描透射电镜(HAADF-STEM)等表征 证明其成功制备了在不同类型的孔中原位生长了 $\mathrm{TiO}_{2}$ 的 MOF 复合材料.

江海龙课题组 ${ }^{[50]}$ 以半胱胺为双功能连接剂, 利用 氨基与 MOFs 中 CUSs 的鳌合，颈基对金属离子的针定， 实现对金属离子的螯合，通过添加硫代乙酰胺来置换金 
属-颈基的配位，以实现 MOF 对于金属硫化物的封装, 制备了MOF@金属硫化物复合材料(图 5). 通过扫描电 子显微镜(SEM)、透射电子显微镜(TEM)、X 射线光电 子能谱(XPS)等表征证明金属硫化物 $\mathrm{NPs}(\mathrm{CdS} 、 \mathrm{ZnS} 、 \mathrm{CuS}$ 和 $\mathrm{Ag}_{2} \mathrm{~S}$ ) 在 MOF 的近表面附着成核和外延生长, 制备出 的复合材料表现出显著增强的电荷分离、转移能力及光 催化性能的提升.

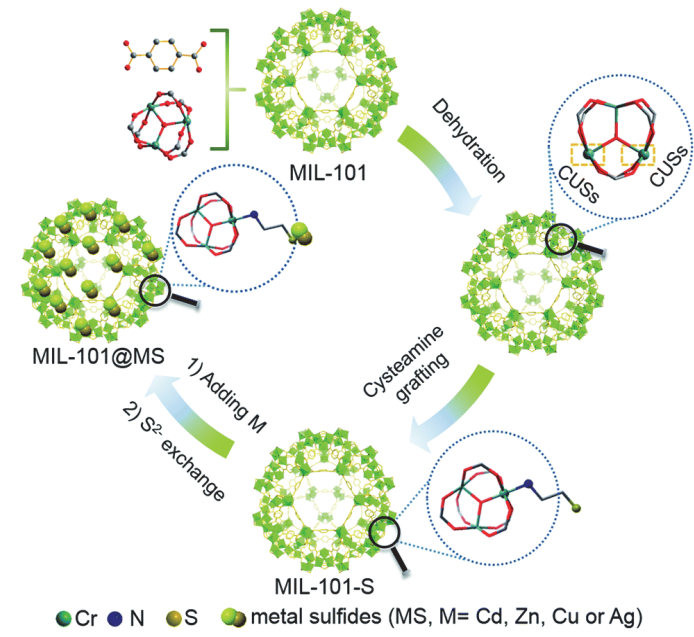

图 5 在无水乙醇中制备 MIL-101@MS 复合材料的路线. 通过去除 MIL-101 中的配位水, 可以暴露 MIL-101 的配位不饱和金属位(CUSs). 颜色键: 铬(青绿色)、氮(紫色)、硫(深黄色)、碳(灰色)、氧(红色), 为 了清楚起见, 省略了氢原子. 改编自文献[50]

Figure 5 Synthesis route to MIL-101@MS composites prepared in anhydrous ethanol. The coordinatively unsaturated metal sites (CUSs) of MIL-101 are exposed by removing coordinated water in MIL-101. Color key: chromium (teal), nitrogen (purple), sulfur (dark yellow), carbon (gray), oxygen (red), hydrogen atoms are omitted for clarity. Adapted from the literature [50]

MOFs 的多孔结构还能提供一定的约束作用, 从而 限制纳米颗粒的生长. 近年来, 研究人员已经通过溶液 浸渍法制备出大量负载有较小尺寸且分散均匀的 $\mathrm{MOF} / \mathrm{NPs}$ 复合材料, 但是单纯的溶液浸渍可能存在前 体化合物沉积在 MOF 的外表面, 并出现纳米颗粒团聚 的现象. 徐强课题组 ${ }^{[40]}$ 开发了一种双溶剂方法(DSM), 可在一定程度上避免 NPs 在 MOF 外表面上的聚集. 此 方法是将 MOF 材料分散在大量的疏水性溶剂(如, 正己 烷)中, 将金属前体溶于亲水性溶剂(如, 水), 控制所含 金属前体的溶液体积等于或略小于吸附剂的孔体积, 利 用毛细作用促进亲水溶液被具有亲水性孔道的 MOFs 所 吸附, 而疏水的溶液环境在分散吸附剂和促进吸附方面 起着重要作用 ${ }^{[40]}$. 由于 MOF 的内表面积比外表面积大 得多, 少量的前驱体水溶液可以进入亲水性孔内, 金属 前驱体在亲水性孔外表面的沉积可以大大减少. 利用该 方法, 结合在相对较低的温度 $\left(200{ }^{\circ} \mathrm{C}\right)$ 下的氢还原, 成 功地将粒径超小的 Pt、 $\mathrm{Pd} 、 \mathrm{Au} 、 \mathrm{Rh}$ 和 $\mathrm{Cu}$ NPs 固定在 MIL-101 的孔内, 减少了其在 MOF 外表面的聚集 ${ }^{[51-53]}$.

此外, 徐强课题组 ${ }^{[54]}$ 通过双溶剂法将金属前体引 入 MOF 孔道, 并首次利用液相浓度控制还原(CCR)的
策略来控制 $\mathrm{Au}^{3+}$ 和 $\mathrm{Ni}^{2+}$ 前体的还原过程，调控了 $\mathrm{AuNi}$ NPs 的大小和位置. 当采用高浓度还原剂进行还原时, 超细 AuNi 合金 NPs 被成功封装到 MOF 的纳米孔中，而 在外表面上没有聚集，相反，如果选择中等还原(MR)方 法，则可能会发生 MNPs (metal nanoparticles，金属纳米 颗粒)的严重团聚. 这是由于通过毛细作用力可以将一 定体积的 $\mathrm{NaBH}_{4}$ 溶液掺入孔隙中, 实现孔内金属前体 的还原，从而最大限度地避免 MNPs 在外表面的聚集. 使用低浓度的 $\mathrm{NaBH}_{4}$ 溶液, 无法完成孔中前体的还原, 部分前体还会重新溶解并从孔中扩散出来，导致 MNPs 在 MOFs 外表面聚集(图 6). 因此通过使用 CCR 策略可 以实现对 MNPs 的大小和位置的调控. 通过能量色散 X 射线光谱(EDX)、电子断层扫描重建、TEM 及 XRD 等 证明了 AuNi NPs 在 MOFs 纳米孔中的成功封装.

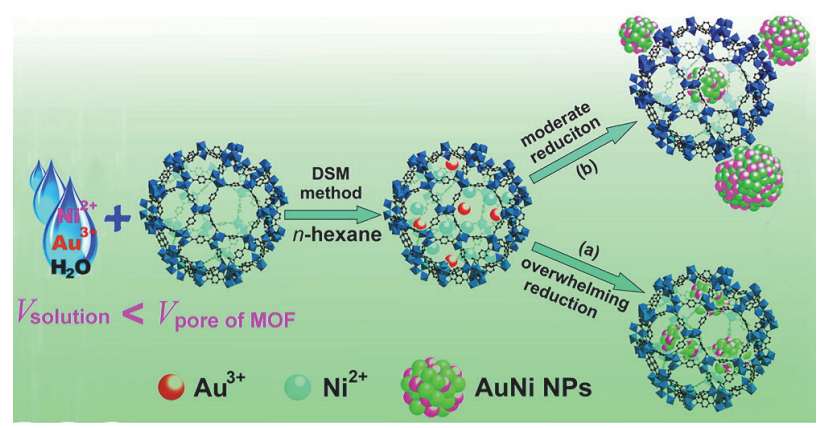

图 6 使用 DSM 结合液相 CCR 策略在 MIL-101 孔道中生长 $\mathrm{AuNi}$ 纳 米颗粒的示意图. 改编自文献[54]

Figure 6 Schematic representation of immobilization of the AuNi nanoparticles by the MIL-101 matrix using the DSM combined with a liquid-phase CCR strategy. Adapted from the literature [54]

李朝晖课题组 ${ }^{[55-56]}$ 通过双溶剂浸渍金属前驱体, 然 后采用光还原法制备了 $\mathrm{Pd} @ \mathrm{MIL}-100(\mathrm{Fe})$, PdAu@MIL-100(Fe), 实现了可见光照射下胺和醇之间 的串联反应中的 $\mathrm{N}$-烷基化. 备菱课题组 ${ }^{[57]}$ 通过双溶剂 的方法, 将含有 $\mathrm{Cd}^{2+}$ 和 $\mathrm{S}^{2-}$ 的混合溶液逐滴滴加到 MIL-101(Cr)的正已烷溶液中, $\mathrm{Cd}^{2+}$ 和 $\mathrm{S}^{2-}$ 溶液通过毛细 作用被吸附到 MOFs 孔道中, 实现了 MIL-101(Cr)孔道 中的 $\mathrm{CdS}$ 的原位生长, 增加了二者的接触面积, 从而增 强了复合材料的光催化 $\mathrm{CO}_{2}$ 的还原能力. 张凤鸣课题 组 ${ }^{[58]}$ 基于 MIL-101 孔的亲水特性, 将 $\mathrm{Cd}^{2+} 、 \mathrm{~S}^{2-}$ 和碳纳 米点(CD)的前体通过一步双溶剂方法引入 MIL-101 的 孔道中, 然后进行热处理, 得到了 $\mathrm{CD} / \mathrm{CdS} @ \mathrm{MIL}-101$ 复 合材料, 在此过程中 MIL-101 的孔道起到了限制纳米颗 粒尺寸的作用，避免了 $\mathrm{CdS}$ 的聚集，实现了纳米颗粒在 MOF 孔道中的均匀分布.

\section{2 沉积法}

\subsection{1 化学沉积法(CVD)}

化学沉积法是在静态真空下, 在密闭的 Schlenk 管 中将去溶剂化的 MOFs 暴露于挥发性金属前驱体的蒸气 中, 金属前驱体在蒸汽压的作用下被引入到 MOF 的孔 
道中, 经过氢还原或简单的热分解处理后得到嵌入 MOFs 的金属 NPs. 与其他复合方法相比, 这种无溶剂 的合成方法在一定程度上避免了溶液浸渍中纳米颗粒 在 MOFs 中分布不均匀的状况. 自 2005 年 Fischer 课题 组首次提出化学气相沉积方法以来, 研究人员采用气相 化学沉积结合热氢解及光解合成了一系列复合材 料 ${ }^{[59-66]}$. Fischer 课题组 ${ }^{[59]}$ 最初选用 MOF-5 作为载体, 通 过嵌入金属前体、氢解得到了一系列金属纳米粒子 MOF 复合材料 MNPs@MOFs $(M=P d 、 A u 、 C u)$, 通过 XRD、 TEM 及 HAADF-STEM 等表征证明了复合材料的成功 制备. 但是由于 MOF-5 的孔径和稳定性等问题, Fischer

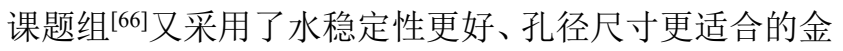
属前体进入 MOF-177 $\left(\mathrm{Zn}_{4} \mathrm{O}(\mathrm{btb})_{2}, \mathrm{btb}=1,3,5\right.$-苯三羧 酸), 通过气相法将 $\left[\mathrm{CpPd}\left(\eta_{3}-\mathrm{C}_{3} \mathrm{H}_{5}\right)\right]_{10},[\mathrm{CpCuCN} t \mathrm{Bu}]_{2}$ 等 挥发性前体加载到去溶剂化的 MOF-177 中, 通过光解 和热氢解转化为复合材料 $\mathrm{Pd} @ \mathrm{MOF}-177$ 和 $\mathrm{Cu} @ \mathrm{MOF}-177$. 此后 Fischer 等[60-61]又尝试以 ZIF 系列, $\mathrm{UiO}$ 系列 MOFs 为载体, 通过化学沉积法制备了 Au@ZIF-8、Au@ZIF-90、Pd@UiO-66、Pd@UiO-67 等 一系列 MOFs@MNPs 复合材料.

Kempe 课题组 ${ }^{[62]}$ 以 $\left[\mathrm{Me}_{3} \mathrm{PtCp}^{\prime}\right]\left(\mathrm{Cp}^{\prime}=\right.$ 甲基环戊二烯 基)为挥发性前体, 通过化学气相沉积在 MOF-177 孔道 中制备了平均粒径为 $2.2 \mathrm{~nm}$ 的铂纳米粒子, 但由于 MOF-177 对水不稳定，限制其应用范围，他们又选择了 水稳定性更好的 MIL-101 ${ }^{[65]}$, 并通过向 MIL-101 中加载 $\mathrm{Pd}$ 前 体化 合物 $\left[\left(\eta^{5}-\mathrm{C}_{5} \mathrm{H}_{5}\right) \mathrm{Pd}\left(\eta^{3}-\mathrm{C}_{3} \mathrm{H}_{5}\right)\right]$, 制 备了 Pd@MIL-101, 实现了对酮加氢反应的高效催化.

\subsection{2 原子层沉积法(ALD)}

传统上, 原子层沉积(ALD) 是用于沉积薄膜的气相 合成技术 ${ }^{[67]}$. 相对于其他技术(例如化学气相沉积/渗 透), ALD 的优势是前体分子仅沉积在具有化学反应性 的材料表面, 进行自限性金属化反应. Hupp 等 ${ }^{[68]}$ 认为适 用于原子层沉积技术的 MOFs 需要满足以下三个条件: 首先, 介孔对于促进 ALD 反应物在 MOFs 中的扩散是 必不可少的, 扩散时间与孔道宽度的平方成反比(与孔 道长度的平方成正比 ${ }^{[69]}$; 第二, 所需的 MOFs 必须具备 良好的热稳定性和水稳定性, 许多 ALD 反应都在 100 $300{ }^{\circ} \mathrm{C}$ 的温度范围内进行, 并以蒸汽作为共反应剂; 最 后, MOF 骨架上必须含有空间导向的官能团(例如-OH 基团)，才能进行自限性金属化反应 ${ }^{[70]}$.

Hupp 课题组合成了一种具有热稳定性、- $\mathrm{OH}$ 配位 以及一维介孔的锆基 MOFs-NU-1000. 其将 NU-1000 的微晶样品置于 ALD 反应器中, 在能够形成合适蒸气 压的温度下，暴露于不同的金属前体中，制备了 $\mathrm{Zn}-\mathrm{AIM}$ 、Al-AIM 、AIM-Me-Ni 、 $\mathrm{AIM}-\mathrm{Me}-\mathrm{Cu}$ 和 AIM-Me-Co (AIM: 在 MOFs 中进行 ALD), 通过 XRD、 SEM、EDX 及电感耦合等离子体发射光谱(ICP-OES)等 证明了复合材料的成功制备 ${ }^{[68,71]}$. 此外, 该团队还通过
原子层沉积, 在 NU-1000 中沉积了一系列独特且高度分 散的金属硫化物催化剂(如硫化钴 ${ }^{[72], ~}$ 硫化镍 ${ }^{[73]}$ 等), 这 种掺入金属硫化物的方法实现了对负载的纳米颗粒的 尺寸和组成的控制.

彭雄义及其合作者 ${ }^{[74]}$ 以 (三甲基(甲基环戊二烯基) 铂(IV) $\left(\mathrm{MeCpPtMe}_{3}\right)$ 为 $\mathrm{Pt}$ 前体, $\mathrm{O}_{2}$ 为反应物, 控制反应 温度为 $80{ }^{\circ} \mathrm{C}$, 通过调节沉积周期控制了 $\mathrm{MOF} / \mathrm{Pt}$ 中 $\mathrm{Pt}$ 的含量. 在其原子层沉积过程中, 发生了四个阶段的反 应(图 7), 包括: (a) Pt 前体吸附在 MOF 表面; (b)用 $\mathrm{N}_{2}$ 吹 扫 MOF 孔道中过量的 $\mathrm{Pt}$ 前驱物; (c)将氧化剂 $\left(\mathrm{O}_{2}\right)$ 引入 MOF 孔道中, 并在其表面发生化学反应; (d)用 $\mathrm{N}_{2}$ 吹扫 过量的氧化剂. 通过 SEM、 $\mathrm{N}_{2}$ 吸附、高分辨率透射电子 显微镜(HRTEM)、EDX、XRD 和 XPS 等表征证明了通 过 ALD 策略实现了 $\mathrm{Pt}$ 纳米粒子在 MOFs 上的均匀分布, 并有效地提高了 MOFs 在可见光照射对染料罗丹明 $\mathrm{B}$ 的 降解能力.

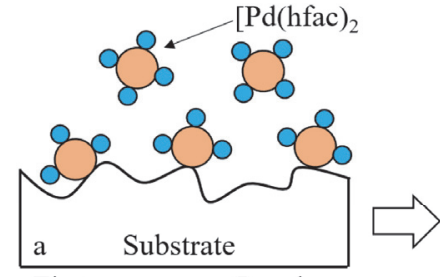

First: precursor (I) pulse

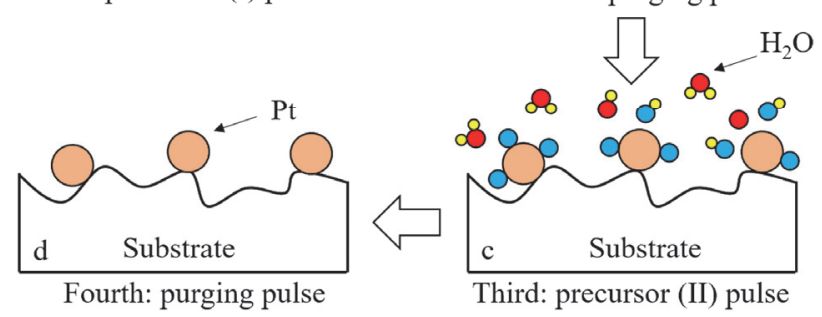

图 7 ALD 反应周期的四个脉冲. 改编自文献[74]

Figure 7 The four pulses of an ALD reaction cycle. Adapted from the literature [74]

\subsection{3 溶剂热沉积法(SIM)}

MOFs 的溶剂热沉积(SIM) 已经被广泛应用于过渡 金属基非均相催化剂的制备 ${ }^{[75-85]}$. PCN-700 因具有以下 结构特点, 被广泛用于溶剂热沉积法沉积其他纳米颗 粒: (1)与 $\mathrm{UiO}$ 系列中的 12 连接的 $\mathrm{Zr}$ 簇不同, PCN-700 中的 $\left[\mathrm{Zr}_{6} \mathrm{O}_{4}(\mathrm{OH})_{8}\left(\mathrm{H}_{2} \mathrm{O}\right)_{4}\right]$ 簇与羧酸酯配体为 8 连接, 剩下 的末端- $\mathrm{OH} / \mathrm{H}_{2} \mathrm{O}$ 配位可以为合成后的金属化提供反应 位点; (2) PCN-700 的大孔隙率有利于金属离子扩散，金 属族上的 $-\mathrm{OH} / \mathrm{H}_{2} \mathrm{O}$ 等基团, 能够促进金属化反应; (3) PCN-700 结构具有一定程度的灵活性, 使框架在金属化 过程中具有结构适应性；(4) PCN-700 具有足够的强度， 可以在溶剂热条件下的金属化过程中保持结晶度. 基于 此, 周宏才课题组 ${ }^{[86]}$ 在 $\mathrm{PCN}-700$ 上进行了 $\mathrm{In}^{3+}$ 的金属 化, 并通过单晶 $\mathrm{X}$ 射线衍射(SCXRD)监控了其相变过 程.

Farha 课题组选用在无水无氧条件下稳定、易与羟 
基发生反应的双(叔丁基亚氨基)双(二甲基氨基)钼 $(\mathrm{VI})\left(\mathrm{Mo}-(\mathrm{am})_{2}\left(\mathrm{im}_{2}\right)\right)$ 为前体, 通过溶剂热沉积法, 实现 了单分散的钼(VI)氧化物在 NU-1000 的 $\mathrm{Zr}_{6}$ 节点上的沉 积, 得到 $\mathrm{MoS}_{x}$-SIM 材料. 通过密度泛理论(DFT)、原位 $X$ 射线吸收光谱(XAS) 以及 XPS 等阐明了 NU-1000 中 Mo 的位置. 将所得到的 Mo-SIM 放置到 ALD 反应器中, 以 $\mathrm{H}_{2} \mathrm{~S}$ 脉冲, 可以得到 $\mathrm{MoS}_{x}-\mathrm{SIM}$, 该催化剂是具有混 合的氧和硫配位的多金属催化剂 ${ }^{[83,87]}$. 此外, Farha、 Hupp 课题组还将 SIM 技术应用于 $\mathrm{Nb} 、 \mathrm{Cu} 、 \mathrm{Co} 、 \mathrm{~V}$ 溶 剂热沉积的 NU-1000 材料的制备中 ${ }^{[75-76,81,88]}$.

Kung 及其合作者 ${ }^{[85]}$ 在羧酸官能化的碳纳米管 $(\mathrm{CNT})$ 上生长带有缺陷的 UiO-66, 制备了 Zr-MOF-CNT 纳米复合材料. 借助溶剂热沉积技术在室温下将具备氧 化还原活性的 $\mathrm{Mn}(\mathrm{II})$ 安装在纳米复合材料中的缺陷位 点, 借助 SEM、XRD、ICP-OES 及 EDX 等证明了 Mn(II) 对 Zr-MOF-CNT 纳米复合材料的修饰, 一维 CNT 提供 的高电导率以及 $\mathrm{Zr}-\mathrm{MOFs}$ 负载的大量氧化还原活性 $\mathrm{Mn}$ 位点显示出良好的电化学性能.

\section{3 固体研磨法}

将具有挥发性的有机金属前体与 MOFs 一起进行无 溶剂或含有少量溶剂的机械研磨, 是一种将 MNPs 沉积 到 MOFs 上的简单且易于操作的方法. 在研磨过程中, 挥发性前体升华的蒸气能够渗透到 MOF 孔道中, 然后 在较温和的温度下处理吸附的前体, 能够制备出嵌入 MOFs 中的金属纳米颗粒 ${ }^{[40]}$.

梁勇及其合作者 ${ }^{[89}$ 将 $\mathrm{NH}_{2}-\mathrm{BDC} 、 \mathrm{Fe}\left(\mathrm{NO}_{3}\right)_{3} \cdot 9 \mathrm{H}_{2} \mathrm{O}$ 、 $\mathrm{Na}_{2} \mathrm{PdCl}_{4}$ 、少量氢氧化四甲基铵溶液 $(\mathrm{TMAOH}$, 体积分 数 $25 \%$ )及直径为 $3 \mathrm{~mm}$ 的氧化锆球放入 $50 \mathrm{~mL}$ 氧化锆 涂层的不锈钢研磨罐进行球磨, 得到了 Fe-MOF-Pd, 然 后将其置于 $\mathrm{N}_{2}$ 保护下碳化, 得到 Fe-Pd@C 复合材料. 通过 XRD、SEM 以及 XPS 等表征证明了 Fe-Pd@C 的 成功制备, 该复合材料表现出高效的污染物降解能力, 并且其磁化曲线表现出明显的滞后现象, 说明了材料在 使用后可以在外加磁场下实现回收利用.

陈超课题组 ${ }^{[90]}$ 将 $\mathrm{ZnO}$ 和 $\mathrm{PdCl}_{2}$ 进行球磨处理, 并在 $\mathrm{H}_{2}$ 气流中还原得到 $\mathrm{Pd} / \mathrm{ZnO}$. 然后将 $\mathrm{Pd} / \mathrm{ZnO}$ 、二甲基咪 唑 $(\mathrm{Hmim}) 、 \mathrm{NH}_{4} \mathrm{Cl}$ 和乙醇的混合物进行球磨以合成 Pd@ZIF-8(图 8). 通过 ICP-OES、XRD、TEM 及 XPS 对其组成和结构进行了表征, 结果显示 MNPs 被封装到 了 MOFs 中.

Maji 等[91]将 $\mathrm{CsX}(\mathrm{X}=\mathrm{Cl} 、 \mathrm{Br}$ 和 I) 与 $\mathrm{PbII} @ \mathrm{AMOF}-1$ 放入研钵中, 研磨 15 20 min, 即可在 AMOF-1 的表面 上形成 CsPbX3 PQD(钻钛矿量子点), PbII@AMOF-1 限 制了量子点的大小并确定了其发光特性, AMOF-1 的存 在增强了 $\mathrm{PQD}$ 的稳定性, 从而使它们能在各种溶剂中 稳定分散, 增强了其可加工性, 该方法可进一步用于合 成各种特定应用的此类复合材料.

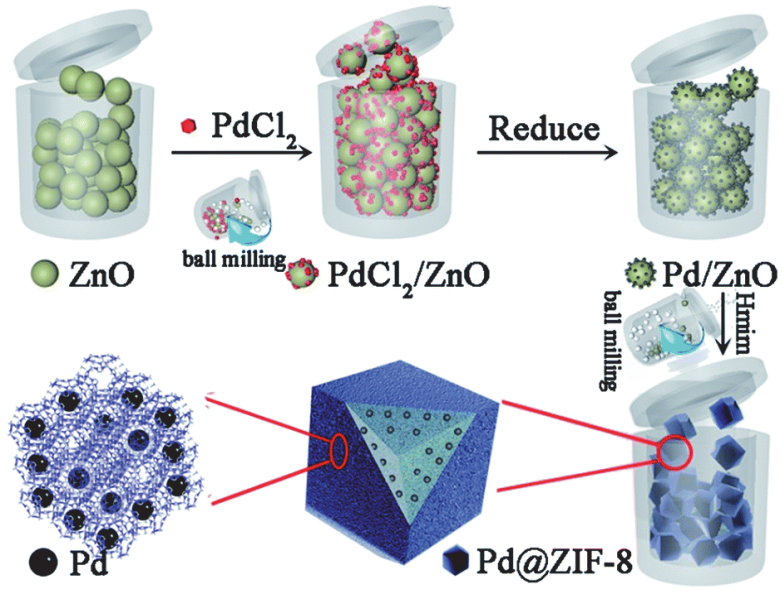

图 8 机械力化学法合成 Pd@ZIF-8 的过程. 改编自文献[90] Figure 8 Synthesis procedure of Pd@ZIF-8 via the mechanochemistry-assisted approach. Adapted from the literature [90]

\section{4 模板合成法}

模板合成法是通过将预先合成的 MNPs 作为成核中 心引入含有 MOFs 生长所需的金属盐和配体的溶液中, 诱导 MOFs 在 MNPs 周围生长, 从而得到 MNPs@MOF 复合材料. 通常, 预先合成的 MNPs 需要用表面活性剂、 封端剂甚至离子来修饰, 以确保 MOFs 的异质外延生长, MNPs 不占据 MOF 空腔, 而是被生长的 MOF 材料所包 围，这种方法可以较容易地控制掺入的 MNPs 的大小、 组成和形态. 但是, 将 MNPs 引入系统有时会给 MOFs 的后续生长带来困难, 因此 MOFs 在 MNPs 表面的可控 生长而不是溶液中的自成核是最大的挑战，近年来，研 究人员采用模板合成法合成了一系列具有核一壳结构的 MNPs@MOF 复合材料 ${ }^{[92-99]}$.

韩冰等 ${ }^{[96]}$ 将制备好的一维 $\mathrm{Au} N \mathrm{NRs}$ 与聚丙烯酸 $(P A A) 、$ 氢氧化铵 $\left(\mathrm{NH}_{3} \cdot \mathrm{H}_{2} \mathrm{O}\right)$ 和异丙醇(IPA) 反应, 得到了 $\mathrm{Au}$ NRs/PAA JNPs (JNPs: Janus 纳米粒子), 然后再将其 加入硝酸锌和二甲基咪唑的异丙醇溶液中搅拌过夜, 得 到了在 AuNR/PAA JNPs 的 PAA 侧生长的 ZIF-8，最后用 乳酸(LA)对 AuNRs 暴露侧表面进行修饰. 通过 TEM、 EDX 等表征证明了 LA-AuNR/ZIF-8 JNPs 的成功制备. 陈莉等 ${ }^{[99}$ 将用聚乙烯吡咯烷酮(PVP)溶液处理后的棒状 的 $\mathrm{Au} N R s$ 放入 $\mathrm{ZIF}-8$ 前体 $\left(\mathrm{Zn}\left(\mathrm{NO}_{3}\right)_{2} \cdot 6 \mathrm{H}_{2} \mathrm{O}\right.$ 和 2-甲基咪 唑) 溶液中, 室温反应, 得到具有核-壳结构的 $\mathrm{Au}$ NRs@ZIF-8.

江海龙课题组 ${ }^{[100]}$ 以 $\mathrm{K}_{2} \mathrm{PdCl}_{4}$ 为金属前体, $L$-抗坏血 酸为还原剂, 聚乙烯吡咯烷酮(PVP)为稳定剂, $\mathrm{KBr}$ 为封 端剂，合成了 Pd NCs. 将合成的 Pd NCs 加入含有 ZIF-8 前体 $\left(\mathrm{Zn}\left(\mathrm{NO}_{3}\right)_{2} \cdot 6 \mathrm{H}_{2} \mathrm{O}\right.$ 和 2-甲基咪唑)的甲醇溶液中, 在 4 두静置 $1 \mathrm{~h}$, 得到了Pd NCs@ZIF-8.

最近, 江海龙课题组 ${ }^{[101]}$ 报道了一种利用 MOFs 封 装八面体 $\mathrm{Cu}_{2} \mathrm{O}$ 纳米晶体 $(\mathrm{NCs})$ 的简便策略, 实现了围绕 $\mathrm{Cu}_{2} \mathrm{O}$ NCs 的 MOFs 外壳(即 HKUST-1)的定向生长(图 9). 该策略定义了精确控制金属氧化物蚀刻速率和 MOFs 结 
晶速率的参数范围. 最后, 用 $\mathrm{NH}_{3} \mathrm{BH}_{3}$ 将复合材料中的 $\mathrm{Cu}_{2} \mathrm{O}$ 还原为 $\mathrm{Cu} N \mathrm{NCs}$, 得到了具有均匀形貌和可控 MOFs 厚度的 $\mathrm{Cu} @$ HKUST-1.

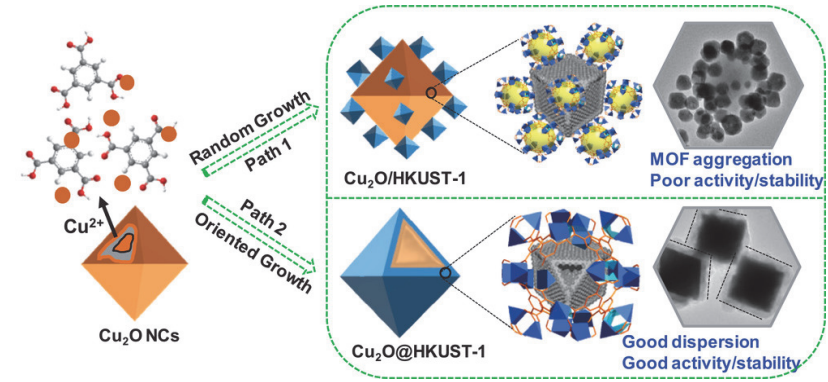

图9 $\mathrm{Cu}_{2} \mathrm{O} @ \mathrm{HKUST}-1$ 取向生长和 $\mathrm{Cu}_{2} \mathrm{O} / \mathrm{HKUST}-1$ 复合材料随机生长 示意图. 改编自文献[101]

Fugure 9 Schematic illustration for the oriented growth of $\mathrm{Cu}_{2} \mathrm{O} @$ HKUST-1 and random growth of $\mathrm{Cu}_{2} \mathrm{O} /$ HKUST-1 composites. Adapted from the literature [101]

\section{MOF 复合材料用于光热肿瘤治疗}

光热疗法(PTT) 是一种极具吸引力的癌症治疗方法, 它能将光能转化为热能, 烧蚀恶性细胞, 最终导致细胞 的不可逆死亡. PTT 的高选择性和微创性使其在治疗大 型原发癌病变方面引起了极大的关注. 当使用近红外 (NIR)激光照射 MOFs 和光热剂组成的复合材料时, 这 些导热纳米粒子还可以通过将热量传递给热响应性药 物载体(例如包覆在导热纳米颗粒上的聚合物和超分子 等), 从而实现多策略协同治疗, 进而改善癌症的治疗 功效 ${ }^{[102-103]}$. 光动力疗法 (PDT) 是利用光敏剂受激之后 产生的活性氧物种(ROS)对恶性细胞和其他病变细胞进 行破环和灭活的光疗法 [104-105]. PTT 结合 PDT 发挥协同 效应，在提高肿瘤治疗效率方面具有巨大的优势 ${ }^{[106-108]}$. 一方面, PTT 技术产生的热可以显著改善血流量和供氧, 从而增强对氧依赖性的 PDT 的肿瘤治疗效果; 另一方 面, PDT 技术产生的 ROS 可以干扰肿瘤生理特性和微环 境条件, 增加癌细胞的热敏感性.

由于传统癌症治疗(如化疗和放疗等)对周围健康细 胞的损伤过大, 因此人们迫切需要设计一种多功能的医 用纳米平台. 该平台不仅可以作为载体以负载用于化疗 的药物分子, 而且还可以结合 PTT/PDT 治疗癌细胞. 通 过在 MOFs 中掺入具有高光热转化效率和良好生物相容 性的纳米颗粒, 进行化学-光热协同治疗逐渐被证明是 一种有效的策略.

\section{$3.1 \mathrm{MOF} /$ 无机纳米颗粒用于光热肿瘤治疗}

具有良好生物相容性及可调的表面等离子体共振 特性的金属纳米粒子, 在生物成像、光热治疗和催化方 面表现出巨大的潜力 ${ }^{[109]}$. 金纳米材料在激光照射过程 中表现出出色的光热稳定性, 并且其具有两个表面等离 子体激元吸收带: 长波长 $(800 \sim 900 \mathrm{~nm})$ 和较弱的短波 长 $(\approx 520 \mathrm{~nm})$ 波段 ${ }^{[110-111]}$, 可以通过调整纵横比来微调 光的长波吸收范围, 实现最大化的光热转换效率. 因此,
近年来许多研究者致力于将不同形式金的纳米颗粒(如 金纳米粒子、金纳米棒、金纳米壳层等)与 MOF 材料进 行复合，以形成具有光热疗效的纳米复合材料.

胡玉玲及其合作者 ${ }^{[93]}$ 以 $\mathrm{Au} \mathrm{NPs}$ 为核, $\mathrm{Cu}_{3}(\mathrm{BTC})_{2}$ 为 壳合成了 $\mathrm{Au} @ \mathrm{Cu}_{3}(\mathrm{BTC})_{2}$ 复合材料, 通过盐酸阿霉素 $(\mathrm{DOX})$ 的进一步装载, 得到了 $\mathrm{DOX}-\mathrm{Au} @ \mathrm{Cu}_{3}(\mathrm{BTC})_{2}$ 材 料. 该材料不仅表现出良好的稳定性、生物相容性、较 高的光热转效率以及 $\mathrm{pH}$ 刺激响应等优异特性, 并且还 可用于近红外辐射和 4-放基苯甲酸拉曼信号增强的癌 细胞光热治疗. 曾乐勇及其合作者 ${ }^{[98]}$ 通过图 10 所示的 合成路线, 将聚乙烯吡咯烷酮(PVP)涂层修饰的 $\mathrm{Au} N \mathrm{~N}$ 封装在 MIL-101- $\mathrm{NH}_{2}(\mathrm{Fe})$ 中，进一步共价结合短肽 (CTVRTSADC, ZD2) 实现了对三阴性乳腺癌细胞 (TNBC) 的特异性靶向作用. AuNS@MOF-ZD2 纳米复合 材料具有良好的生物相容性、有效的 $\mathrm{T} 1$-加权核磁共振 (MR)弛豫和高效的光热转化能力, 表现出了良好的肿 瘤抑制效果以及低生物毒性，所处理的小鼠显示出近 $100 \%$ 的成活率. 该复合材料是专门针对 TNBC 的可视 化治疗纳米探针的理想候选者, 并且在乳腺癌的诊断和 治疗领域具有潜在的应用价值.

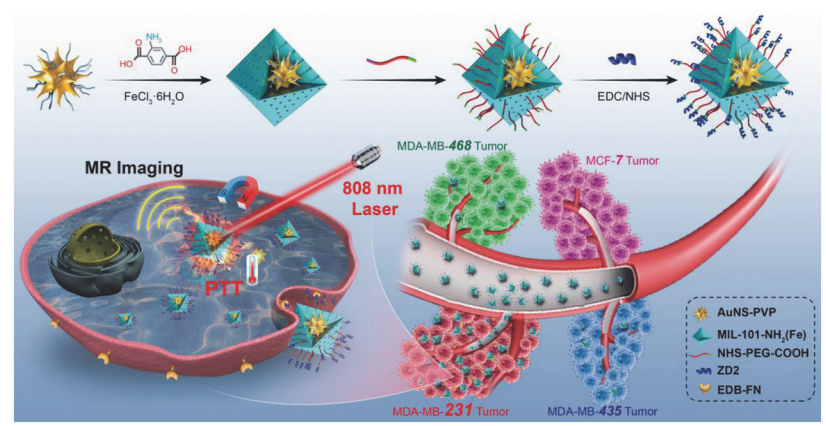

图 10 AuNS@MOF-ZD2 纳米探针的合成示意图, 及其在 T1-加权 MR 成像和光热疗法中特别针对 MDA-MB-231 肿瘤(TNBC)的应用. 改编自文献[98]

Figure 10 Schematic illustration of the synthesis of AuNS@MOF-ZD2 nanoprobes, and application for T1-weighted MR imaging and photothermal therapy specifically toward MDA-MB-231 tumor (TNBC). Adapted from the literature [98]

唐志勇课题组 ${ }^{[92]}$ 选择在 PVP 修饰的金纳米棒上原 位生长 ZIF-8, 合成了具有核-壳结构的 AuNR@ZIF-8. ZIF-8 壳层可减少 Au NR 才聚的可能, 降低游离的 $\mathrm{Au}$ $\mathrm{NR}$ 的毒性, 提高纳米材料的生物相容性. 在 ZIF-8 壳层 进行化疗药物 DOX 负载后, 借助 $\mathrm{Au} N \mathrm{NR}$ 的高光热转换 性能, 在 $808 \mathrm{~nm}$ 的近红外光的照射下, 实现了 $\mathrm{pH}$ 和 NIR 光双重刺激响应的 DOX 释放, 实现优异的化学-光 热协同的癌症治疗.

林君课题组 ${ }^{[97]}$ 选择了以星状的金纳米颗粒为核, ZIF-8 为壳, 合成了装载了 DOX 的卵黄壳结构的 $\mathrm{Au} @ Z \mathrm{ZIF}-8-\mathrm{DOX}$ (图 11a). 星状的金纳米颗粒在 NIR-II $(1000 \sim 1350 \mathrm{~nm})$ 区域具有很强的吸收能力, 可以实现 更深的组织穿透，表现出更好的光热性能，在 $1064 \mathrm{~nm}$ 的激光照射下, 其还可以作为红外光热和光声显像剂. 
如图 11b 11d 所示, 体内外实验结果表明, 纳米复合材 料具有独特的生物相容性及 PTT-化疗协同的肿瘤治疗 能力.
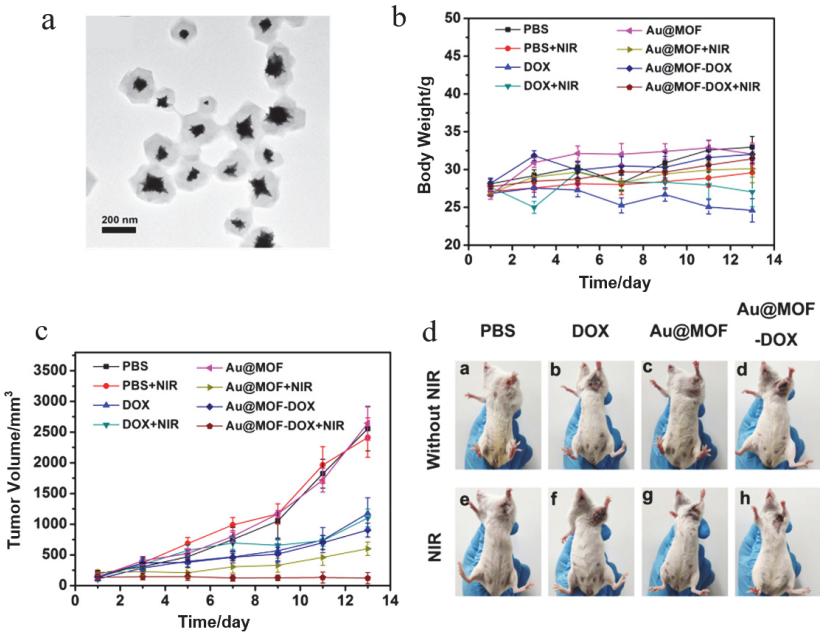

图 11 (a) 卵黄壳结构 Au@MOF TEM 图像; (b) 体内 DOX、 Au@MOF、Au@MOF-DOX 分别静脉注射于荷瘤小鼠体内, 经 1064 $\mathrm{nm}$ 激光照射或不照射处理, 各组荷瘤小鼠在治疗期间的平均体重; (c) 各组荷瘤小鼠的相对肿瘤体积(归一化); (d) 不同处理后荷瘤小鼠 的代表性照片. 改编自文献[97]

Figure 11 (a) TEM images of yolk-shell structured Au@MOF; (b) in vivo DOX, Au@MOF, and Au@MOF-DOX were injected intravenously to the tumor-bearing mice and treated with or without $1064 \mathrm{~nm}$ laser irradiation. The average body weight of tumor-bearing mice in each group during the treatment periods; (c) the relative tumor volumes (normalized) of tumor-bearing mice in each group; (d) the representative photographs of tumor-bearing mice after different treatments. Adapted from the literature [97]

韩冰及其合作者 ${ }^{[96]}$ 同样选择了 AuNR 和 ZIF-8，合 成了一种具有各向异性的 JNPs(图 12). 该工作将聚丙烯 酸(PAA)选择性地连接到 AuNR 的一侧用以辅助 ZIF-8 的生长, 对暴露的 AuNR 另一侧进行靶向剂乳糖酸(LA) 的修饰, 实现了 DOX 药物的装载和肿瘤的特异性靶向. 此外, $\mathrm{Au}$ 的高对比度使 LA-AuNR/ZIF-8 JNPs 能够实现 电子计算机断层扫描(CT)成像、 $\mathrm{pH}$ 响应和近红外刺激 引起的 DOX 缓释、肿瘤特异性靶向以及协同化疗和光 热治疗的有效结合.

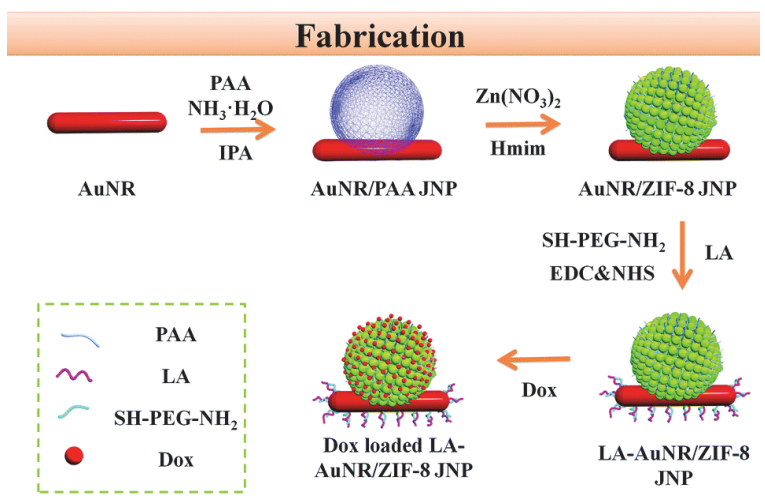

图 $12 \mathrm{LA}-\mathrm{AuNR} / \mathrm{ZIF}-8 \mathrm{JNP}$ 的制备示意图. 改编自文献[96]

Figure 12 Schematic illustration of fabricating LA-AuNR/ZIF-8 JNPs. Adapted from the literature [96]
吴爱国课题组 ${ }^{[95]}$ 采用简单的一步法制备了一系列 具有良好近红外吸收性能的多孔核一壳结构纳米粒子 $\left(\mathrm{NH}_{2}-\mathrm{MOFs} @ \mathrm{Au}\right.$ shell). 然后对其进行 $\mathrm{Pt}$ 及光敏剂二氢 卟酚 e6 (Ce6)的负载, 得到了 PUA-Ce6(Pt@UiO-66- $\mathrm{NH}_{2}$ @) $\mathrm{Au}_{\text {shell-}} \mathrm{Ce}$ )(如图 13). a

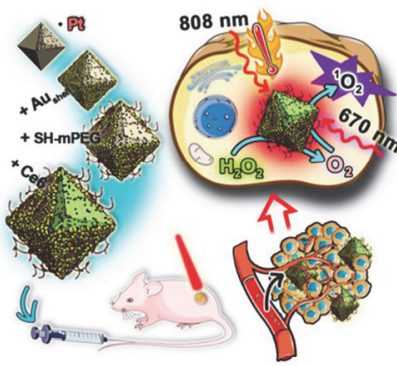

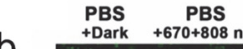

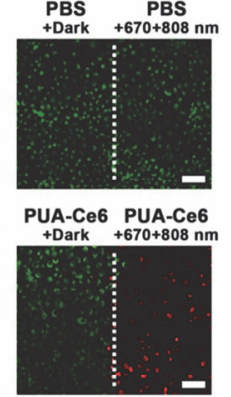

C

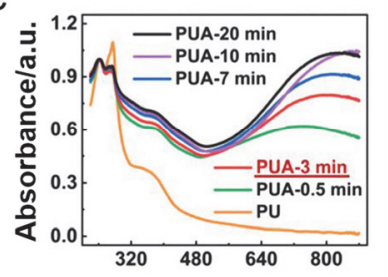

Wavelength/nm

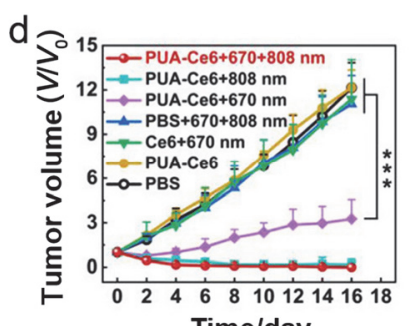

Time/day
图 13 (a) 制备 PUA-Ce6 的流程以及通过将肿瘤内的 $\mathrm{H}_{2} \mathrm{O}_{2}$ 转化为 $\mathrm{O}_{2}$ 应用于 PTT 潜在增强的 PDT 结合以进行肿瘤治疗的情况; (b) 添加 PBS 或 PUA-Ce6 置于黑暗中或用 670 和 $808 \mathrm{~nm}$ 激光照射餒育的 MCF-7 细胞的荧光图像, 处理 $5 \mathrm{~min}$ (用 Calcein-AM/PI 染色, 绿色表示 活体，红色表示死亡); (c) 不同反应时间下，PUA 水溶液对应的紫外 可见吸收光谱; (d)不同处理后小鼠的肿瘤体积曲线变化(每组 5 只小 鼠). 改编自文献[95]

Figure 13 (a) Schematic illustration for the preparation of PUA-Ce6 and its application on combination of PTT and potential enhanced PDT by converting intratumor $\mathrm{H}_{2} \mathrm{O}_{2}$ into $\mathrm{O}_{2}$ for tumor therapy; (b) fluorescent images of MCF-7 cells incubated with PBS or PUA-Ce6 nanoparticles with or without 670 and $808 \mathrm{~nm}$ laser irradiation, each for 5 min separately (stained by Calcein-AM/PI, green for live and red for dead); (c) the corresponding UV-vis-NIR absorbance spectra of PUA aqueous solution at different reaction times; (d) tumor volume curves change of mice after different treatments (5 mice per group). Adapted from the literature [95]

$\mathrm{Au}$ 的引入将材料的吸光范围拓宽至近红外部分, $\mathrm{Pt}$ 纳米颗粒可以解决肿瘤低氧环境对 PDT 的限制, 催化 肿瘤细胞内的 $\mathrm{H}_{2} \mathrm{O}_{2}$ 产生 PDT 所需要的 $\mathrm{O}_{2} . \mathrm{Ce} 6$ 的引入 不仅增加了苂光成像效果(图 13b), 并且还可加强 PDT 效果. 体内外实验表明，该复合材料具有良好的生物相 容性和显著的近红外光热转换能力, 通过发挥 PDT 和 PTT 的协同作用，有效抑制了小鼠肿瘤细胞的生长.

量子点具有显著的尺寸效应，基本上高于特定域值 的光都可吸收, 并且其能够承受多次的激发和光发射并 保持稳定. 因此，不同量子点与 MOFs 形成的复合材料 在光热领域的潜在应用价值引起了研究者的关注. 黑磷 量子点(BQ), 由于具有量子约束和边缘效应, 表现出单 线态氧 $\left({ }^{1} \mathrm{O}_{2}\right)$ 的生成能力和光热转换效率等光学性质, 可 用于光动力治疗和光热治疗 ${ }^{[12-113]}$. 雷剑平课题组 ${ }^{[114]}$ 采 
用图 14 所示流程, 通过逐步原位生长的方法, 将黑磷量 子点和过氧化氢酶分别封装到 MOFs 的内层和外层. 集 成的 BQ-MIL@cat-fMIL 体系可作为串联催化剂, 外层 过氧化氢酶可以将肿瘤微环境中的 $\mathrm{H}_{2} \mathrm{O}_{2}$ 转化为 $\mathrm{O}_{2}$, 然 后生成的 $\mathrm{O}_{2}$ 扩散到 MOFs 封装的 $\mathrm{BQ}$ 内层, 实现单线态 氧的高效产生, 最终缓解肿瘤内缺氧并改善 PDT 效果. 此外, BQ 和过氧化氢酶的封装还表现出了较强的热疗 作用, 为开发具有抗缺氧肿瘤微环境的治疗平台提供了 一种方法.

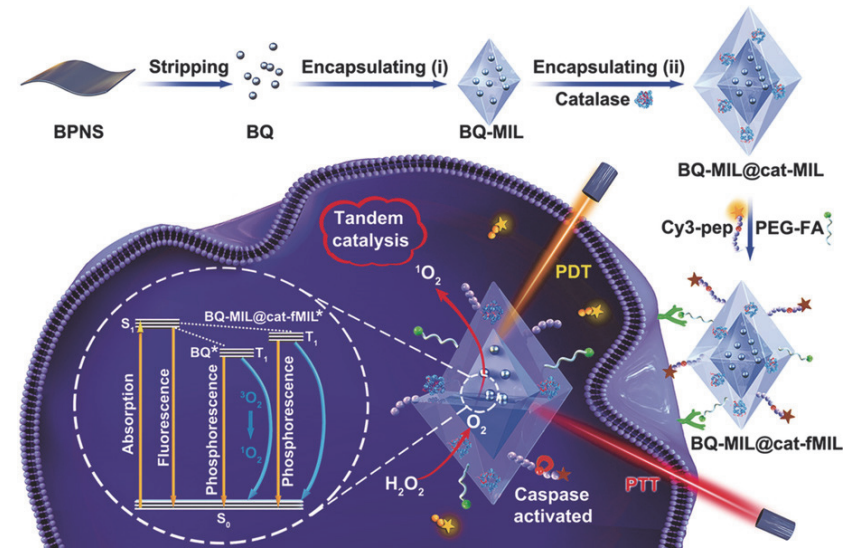

图 $14 \mathrm{BQ}$ 和过氧化氢酶在 MOF 层中的逐步组装及其作为串联催化 剂增强对缺氧肿瘤细胞的治疗. 改编自文献[114]

Figure 14 Stepwise assembly of BQ and catalase in MOF layers and its application as tandem catalyst for enhanced therapy against hypoxic tumor cells. Adapted from the literature [114]

石墨烯量子点(GQDs)具有良好的近红外吸收性能、 较高的光热转换效率、优异的导热性和低毒性 ${ }^{[115]}$, 作为 一种光敏剂受到越来越多的关注. 朱钰方课题组 ${ }^{[116]}$ 借 助 ZIF-8 中 2-甲基咪唑的 N-H 基团与 GQDs 石墨烯量子 点上的羟基、环氧基和羧基之间的氢键作用, 诱导 GQDs 吸附在原位装载了 DOX 的 ZIF-8 纳米颗粒上, 实 现了 $\mathrm{pH}$ 响应的细胞内药物释放以及近红外辐射诱导的 光热转化, 通过两者的协同, 在肿瘤治疗中取得了良好 的效果.

磁性材料的引入不仅可以为外磁场提供磁性靶向, 还可以很好充当 $\mathrm{T} 2$ 造影剂, 应用于癌症治疗临床应用 中磁共振成像(MRI). 值得注意的是, 较分子靶向而言, 基于物理相互作用的磁性靶向, 其优势在于不受特定受 体表达或正常组织中受体的非特异性表达的限制 ${ }^{[117-118]}$, 并且大多数含磁性氧化铁纳米颗粒(IONPs)的药物载体 不仅具有良好的生物相容性、生物降解性、磁性和高化 学稳定性等固有优势, 还具有用作 NIR 光吸收剂和磁性 对比剂的能力 ${ }^{[119-120]}$, 因此得到了广泛的研究. 将 $\mathrm{Fe}_{3} \mathrm{O}_{4}$ 等磁性材料与 MOFs 复合, 已逐渐成为构造多功能纳米 平台的重要途径. 杨飘萍及其合作者 ${ }^{[32]}$ 通过在 $\mathrm{Fe}_{3} \mathrm{O}_{4} / \mathrm{ZIF}-8$ 复合材料中引入 $\mathrm{Au}_{25}(\mathrm{Capt})_{18}$ 簇, 不仅在近 红外光照射下实现了光动力效应以及超强光热效应的 协同, 而且还充分发挥了磁性材料的远程控制靶向作用 和 MRI 成像功能, 在肿瘤成像、磁性靶向、多策略协同
癌症治疗方面展示出重要潜力(图 15).
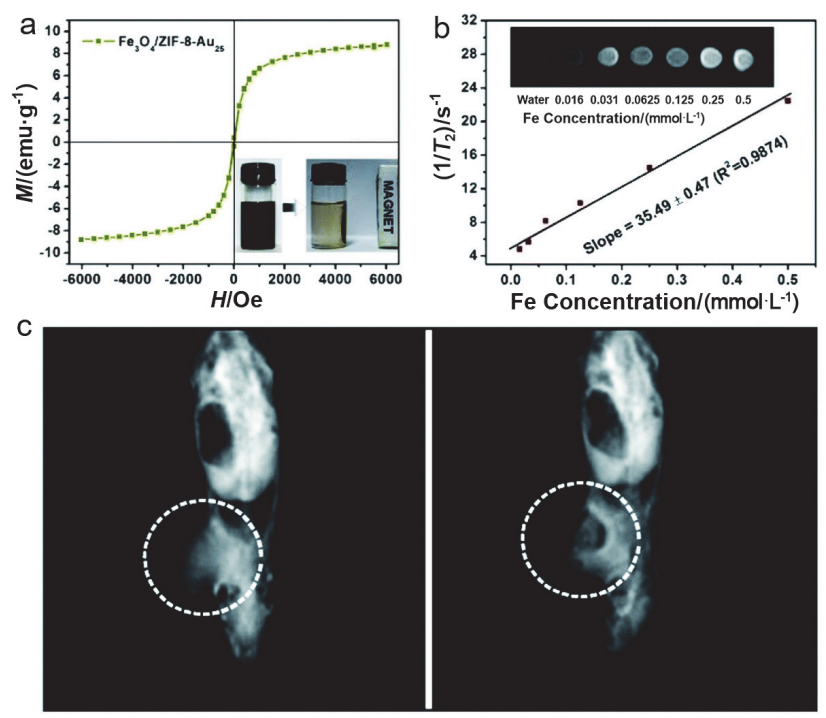

图 15 (a) $\mathrm{Fe}_{3} \mathrm{O}_{4} / \mathrm{ZIF}-8-\mathrm{Au}_{25}$ 样品的场相关磁化回路; (b) 使用 3T MR 扫描仪记录的 $\mathrm{Fe}_{3} \mathrm{O}_{4} / \mathrm{ZIF}-8-\mathrm{Au}_{25}$ 纳米复合材料的 $\mathrm{T} 2$ 加权 MRI 图像; (c) 使用 $\mathrm{Fe}_{3} \mathrm{O}_{4} / \mathrm{ZIF}-8-\mathrm{Au}_{25}$ 样品在体内进行 MRI 成像. 在注射 IZA 之前 (左)和之后(右)拍摄 MRI 图像. 改编自文献[32]

Figure 15 (a) Field-dependent magnetization loop of the $\mathrm{Fe}_{3} \mathrm{O}_{4} / \mathrm{ZIF}-8-\mathrm{Au}_{25}$ sample; (b) T2-weighted MR images of $\mathrm{Fe}_{3} \mathrm{O}_{4} / \mathrm{ZIF}-8-\mathrm{Au}_{25}$ nanocomposite recorded using a 3T MR scanner; (c) MR imaging for in vivo mapping using $\mathrm{Fe}_{3} \mathrm{O}_{4} / \mathrm{ZIF}-8-\mathrm{Au}_{25}$ sample. MR images were taken before (left) and after (right) injection of IZA. Adapted from the literature [32]

镧掺杂的上转换纳米粒子是一种在低功率光激发 条件下具有反斯托克斯位移特性的新型纳米材料 ${ }^{[121]}$, 能够将具有高组织穿透性的近红外光转化为高能紫外/ 可见光 ${ }^{[122]}$, 可作为潜在的体内光调制器, 在生物传

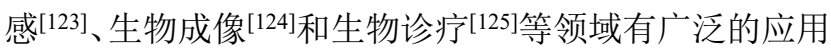
前景.

林君及其合作者 ${ }^{[126]}$ 通过将具有人乳腺癌细胞靶向 能力的 AS1411 适配体共价偶联在 UCNPs@ MIL-100(Fe)表面后, 进一步装载药物, 实现了高生物 相容性和 $\mathrm{pH}$ 响应靶向给药的癌症诊断和治疗. 杨飘萍 及其合作者 ${ }^{[127]}$ 通过液 - 固 - 溶法 (LSS) 制备了 UCNPs@MIL-100(Fe)复合材料, 其在 $808 \mathrm{~nm}$ 的激光照 射下, 能够产生大量的差基自由基 $(\cdot \mathrm{OH})$ 以及足够的热 量, 进而抑制和破环肿瘤细胞. 此外, MOFs 的多孔结构 和高比表面积有助于大量 DOX 的装载, 实现了在上转 换发光和 MRI 成像指导下, 光动力、光热和化学疗法的 多模式协同体内外肿瘤细胞治疗.

普鲁士蓝 $(\mathrm{PB})$ 纳米粒子是一类具有良好光热消融 能力的无机材料, 并已被美国食品和药物管理局(FDA) 批准为可逆转过度辐射损害的临床药物. 其高效的光热 转换效果源自 $\mathrm{Fe}$ (II) 和 $\mathrm{Fe}$ (III) 之间的电荷转移跃 迁 ${ }^{[128-129]}$. 陈乾旺课题组 ${ }^{[130]}$ 采取逐层生长法制备了可包 覆药物的 $\mathrm{PB} @ \mathrm{MIL}-100(\mathrm{Fe})$ 复合材料, 通过光热-化疗 的联合应用抑制了肿瘤细胞的生长. 然而, 含铁化合物 
的非胃肠给药会干扰铁的稳态, 并表现出一定的细胞毒 性 ${ }^{[131]}$. 因此, 其又通过在 PB 核上原位生长 ZIF-8 外壳, 开发了新型的 CSD-MOFs 纳米复合材料(图 16). 该复合 材料具有良好的生物相容性、极高的载药量和持续有效 的 $\mathrm{pH}$ 响应药物缓释, 成功实现了磁共振成像/苂光光学 成像(FOI)引导的体内同步诊断与协同化疗-热疗的肿瘤 治疗 ${ }^{[132]}$.
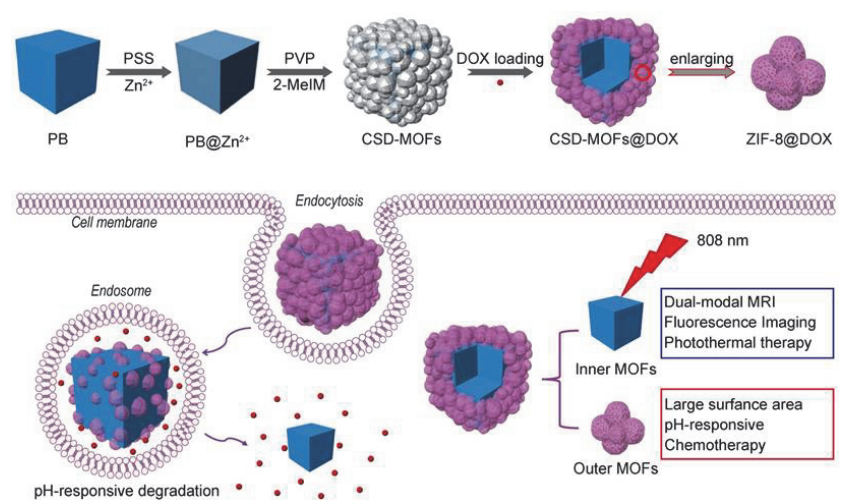

图 16 (a) CSD-MOFs 的合成程序示意图; (b) 示意图: CSD-MOFs@DOX 作为一种有效的多模式协同肿瘤治疗药物. 改编 自文献[132]

Figure 16 (a) Schematic illustration of synthetic procedure of CSD-MOFs and (b) schematic representation: CSD-MOFs@DOX as an effective multi-model therapeutic agents for synergistic tumor therapy. Adapted from the literature [132]

具有良好吸光性能及高效光热转换能力的无机纳 米材料, 已被广泛地应用于光热领域的研究. 然而, 对 于无机纳米颗粒来说, 如何实现复合后颗粒高度分散以 及大小、位置可控的同时, 使其具有高血液相容性、低 细胞毒性、高药物负载以及肿瘤细胞的靶向性, 并最终 实现多模式成像引导的化疗、PTT、PDT 治疗协同的肿 瘤治疗是研究者需要考虑的重点.

\subsection{MOF/有机光敏剂用于肿瘤治疗}

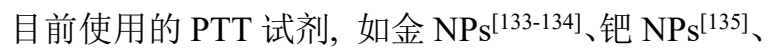

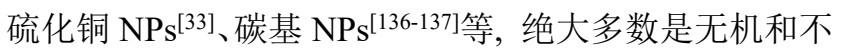
可降解的材料, 临床治疗后可能会残留在体内, 存在长 期毒性等潜在危险. 近年来, 基于小分子的有机染料 (如卟啉、吲哚菁绿和庚烷等) ${ }^{[138]}$ 和聚合物纳米颗粒(如 聚吡咯、聚多巴胺和聚苯胺等 ${ }^{[139]}$ 等 PTT 试剂相关功能 复合材料的开发受到了极大关注.

\subsubsection{MOF/有机染料用于肿瘤治疗}

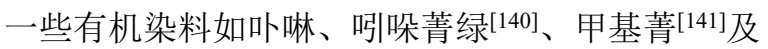
其衍生物因具有多种功能而具备潜在的临床应用价值. 研究人员通过将有机染料分子作为有机配体引入到 MOF 材料中, 或通过以 MOFs 为载体实现有机染料的 负载等方法将二者的优势结合, 制备出具有高光热性能 的 MOFs 及 MOF 复合材料, 在光热肿瘤治疗中表现出 巨大的应用潜力.
卟啉和类卟啉化合物因对近红外光比较敏感，常被 用作光疗剂用于癌症治疗. 卟啉类 MOFs 是由卟啉类光 敏剂和金属离子/簇自组装而成的，该类 MOFs 具有较 高的光敏剂负载能力、较高的光热转化能力, 并且其可 以在光照条件下产生活性氧物种, 作为一种极具吸引力 的光功能多孔材料备受关注.

吴成铁及其合作者 ${ }^{[142]}$ 通过简单的溶剂热法制备了 具有高效光热转换效率和 $\mathrm{T} 1$ 加权核磁共振成像能力的 超薄 Cu-TCPP MOF 纳米片. 谢志刚课题组 ${ }^{[143]}$ 将具有光 活性四 (4-羧苯基) 卟吩 (TCPC) 配体成功地引入到 Hf-UiO-66 结构中, 实现了 PDT 和 PTT 的协同作用(图 17). TCPC-UiO 中的 Hf 团簇可以通过重原子效应大大增 强激光照射下的光疗性能, 并赋予 MOFs CT 成像能力. 该 MOFs 对 $\mathrm{H} 22$ 荷瘤小鼠肿瘤细胞表现出了明显的抑制 作用(抑制率高达 $90 \%$ ), 是 $\mathrm{CT} /$ 热/光声成像应用的潜在 平台.

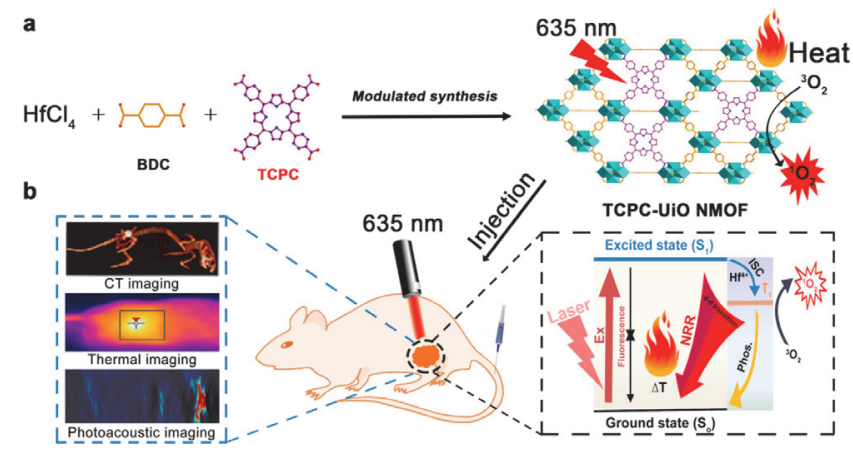

图 17 用于癌症治疗的光激活 TCPC-UiO 的合成及其机理. (a) TCPC-UiO NMOF 的合成及激光辐照下产热和单线态氧的原理描述; (b) 在 $\mathrm{CT} /$ 热/光声成像引导下在体内利用单一光源进行联合癌症治 疗的光物理机制(Phos, 磷光; NRR, 无辐射复合; ISC, 系间窝越). 改 编自文献[143]

Figure 17 Synthesis and mechanism for cancer therapy of TCPC-UiO by light activation. (a) Synthesis of TCPC-UiO NMOF and schematic description of heat and singlet oxygen generation under laser irradiation; (b) photophysical mechanism for cancer therapy under light activation (Phos., phosphorescence; NRR, nonradiative recombination; ISC, intersystem crossing) of a combination therapy utilizing a single light source in vivo guided by $\mathrm{CT} /$ thermal/photoacoustic imaging. Adapted from the literature [143]

刘庄课题组 ${ }^{[144]}$ 按如图 18 所示流程通过自组装 $\mathrm{Mn}^{2+}$ 离子和近红外染料 IR825 桥接配体合成了新型 NMOPs, $\mathrm{Mn}^{2+}$ 提供了很强的 $\mathrm{T} 1$ 加权磁共振成像对比度, IR825 展示出高效的近红外光热转换效率, 表面涂覆的 多巴胺(PDA)壳层使纳米颗粒具备良好的生理稳定性. Mn-IR825@PDA PEG NMOPs 表现出有效的肿瘤靶向 性, 实现了 MRI 引导的体内肿瘤的光热消融治疗, 同时 复合材料可通过肾脏迅速排出体外, 最大程度地减少长 期毒性.

除了通过配体的形式将具有光热性质的染料分子 引入到 MOFs 中, 另一种更常见的方法是将 MOFs 作为 负载染料分子的多孔载体. 研究人员以 MOFs 作为纳米 
载体来改善花菁染料的生物利用度, 并将其用于肿瘤治 疗 ${ }^{[145-146]}$. 刘刚课题组 ${ }^{[147]}$ 成功地开发了如图 19 所示的 负载了透明质酸 $(\mathrm{HA})$ 和吲哚菁绿 $(\mathrm{ICG})$ 的 MIL-100 $(\mathrm{Fe})$ (MOF@HA@ICG NPs)多功能纳米平台. 其具有较高的 药物负载、良好的近红外吸收及高效的光热转换能力, 实现了肿瘤细胞的靶向性、T2 加权 MRI 成像以及化疗、 光热协同的肿瘤治疗.

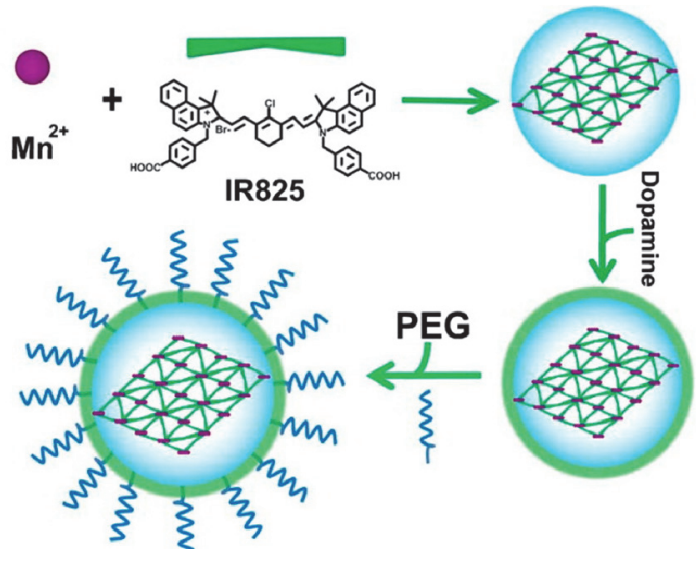

图 18 Mn-IR825@PDA-PEG 的合成过程. 改编自文献[144]

Figure 18 Schematic illustration to show the fabrication process of Mn-IR825@PDA-PEG. Adapted from the literature [144]

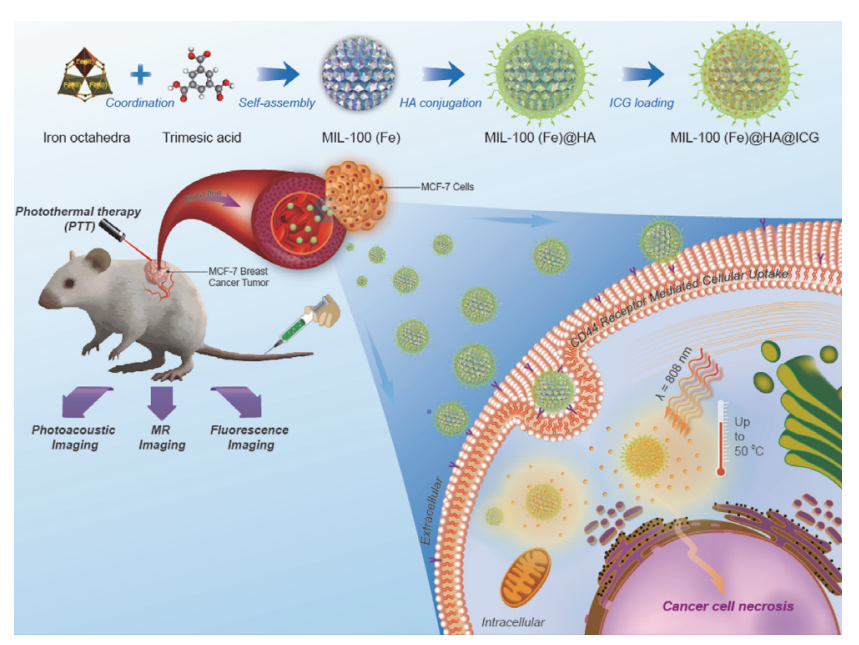

图 19 MIL-100(Fe) NPs 的合成过程、HA 偶联、ICG 加载和多模态 成像引导 PTT 的示意图. 改编自文献[147]

Figure 19 Schematic representation of the synthesis procedure, HA conjugation, ICG loading, and multimodal imaging-guided PTT of MIL-100(Fe) NPs. Adapted from the literature [147]

\subsubsection{MOF/有机聚合物用于肿瘤治疗}

与目前广泛应用的无机纳米颗粒相比, 有机聚合物 如聚吡咯(PPy)、聚多巴胺、聚苯胺(PAN)等表现出较强 的近红外吸收和光稳定性. 近年来, 结合了结晶态 MOFs 的优点和聚合物柔韧性的 MOFs/有机聚合物复 合材料受到了广泛的关注.

聚吡咯是一种稳定的、生物相容性较好的聚合物, 在近红外区具有很强的光吸收能力, 是一种潜在的用于 体内外 PTT 治疗的光热剂[38,148-150]. 因此研究者们开发
了制备 PPy 与 MOFs 的复合材料的多种方法，并测试了 复合材料对肿瘤作用效果.

王春刚课题组 ${ }^{[150]}$ 制备了具有核 - 壳结构的 PPy@MIL-100, 进而负载抗癌药物 DOX, 得到了在 NIR 照射下具有出色光热效应以及低 $\mathrm{pH}$ 下药物可控缓 释的 MOF 复合材料-PPy@MIL-100(Fe) NCs. 其能实 现如图 20 所示的用于肿瘤细胞的 $\mathrm{MRI} /$ 光声成像(PAI) 和化疗-光热协同的肿瘤治疗.

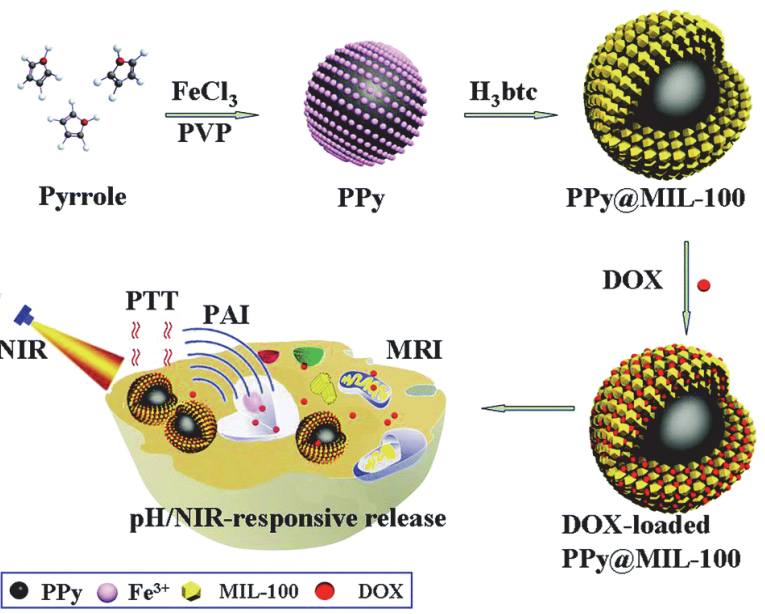

图 20 PPy@MIL-100(Fe) NCs 作为药物载体用于双模成像和具有 $\mathrm{pH} / \mathrm{NIR}$ 响应的化疗和光热治疗的合成策略示意图. 改编自文献[150] Figure 20 Schematic illustration of the synthetic strategy for PPy@MIL-100(Fe) NCs as pH/NIR-responsive drug carriers for dualmode imaging and synergistic chemo-photothermal therapy in vitro. Adapted from the literature [150]

孟召伟及合作者 ${ }^{[151]}$ 以 MIL-53 为微反应器, 原位生 长了聚吡咯纳米颗粒，制备了 PPy@MIL-53 纳米复合材 料(图 21). PPy@MIL-53 结合了 MOFs 的高载药能力、 磁共振成像能力以及 PPy 纳米颗粒优异的 PTT 能力和 良好的生物相容性. 将 DOX 作为抗癌模型药物加载于 PPy@MIL-53 中, 得到了PPy@MIL-53/DOX. 肿瘤附近 的酸性环境及近红外激光辐照会引发药物释放, 并且复 合材料能够充分发挥光热-化学药物在癌症治疗方面的 协同效应.

与其他聚合物类的 PTT 试剂相比, PDA 由于在光热 转化中具有很强的 NIR 吸收性和非辐射转变能力 ${ }^{[152]}$, 在 PTT 肿瘤治疗以及光声造影剂方面具有巨大的应用 潜力. 孟宪伟团队 ${ }^{[153]}$ 通过一锅法合成了具有高 DOX 负 载量的 ZIF-8, 然后用 PDA 及在一定温度下可溶的相变 材料(十四烷醇, PCM)对其表面进行修饰. 在近红外光 的辐照下, PDA 具有高效的光热肿瘤治疗能力, 高温促 使 PCM 溶解, 肿瘤区域的酸性环境可以使药物载体 ZIF-8 降解, 实现了药物的精确释放, 抑制了肿瘤的生 长. 陈学思课题组 ${ }^{[154]}$ 则按图 22 所示方法在 MIL-100 表 面涂覆聚多巴胺修饰的透明质酸(HA-PDA), 进一步负 载具有良好光热性能的姜黄素, 实现了肿瘤细胞的靶向 性、体内 PAI 成像以及化疗、光热协同的肿瘤治疗. 


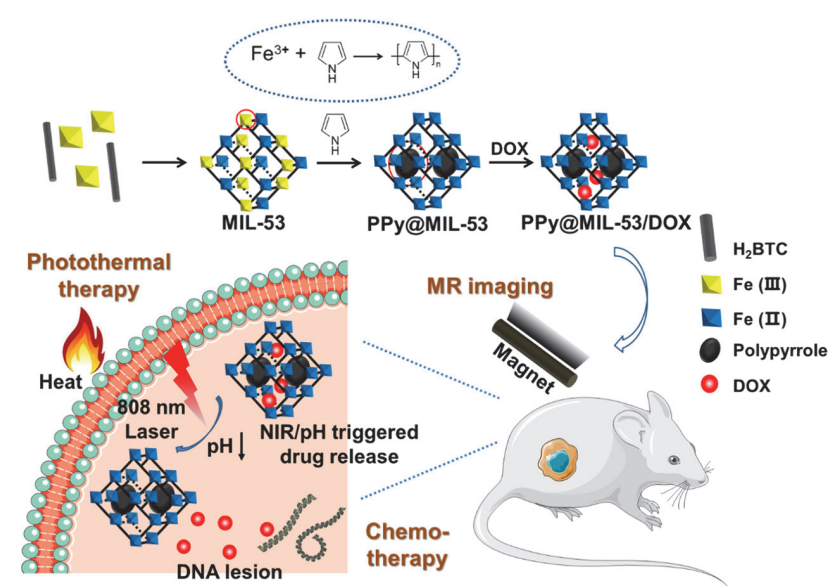

图 21 PPy@MIL-53/DOX 的合成及用于光热化学疗法和肿瘤 MRI 的 流程. 改编自文献[151]

Figure 21 Illustration of PPy@MIL-53/DOX synthesis for photothermal-chemotherapy and MRI of tumors. Adapted from the literature [151]

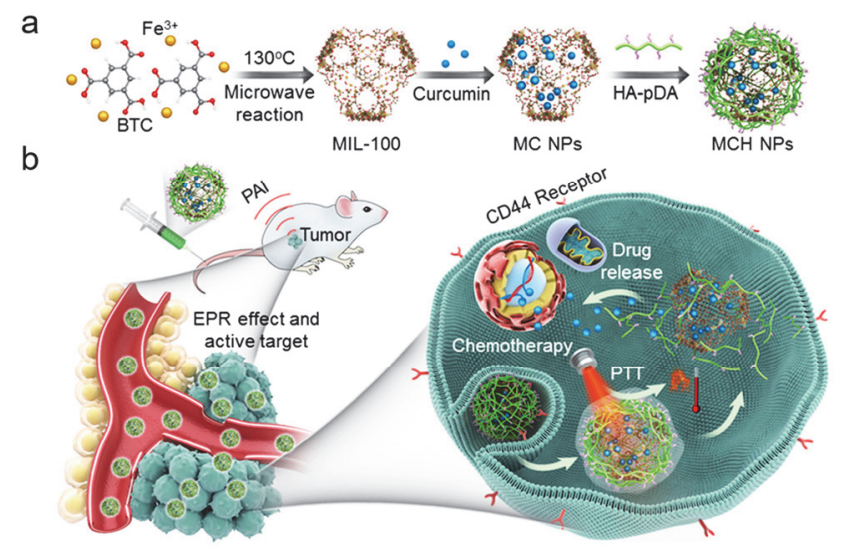

图 22 (a) MCH NPs 的制备流程; (b) MCH NPs 用于 PAI 引导的化学/ 光热联合肿瘤治疗的示意图. 改编自文献[154]

Figure 22 (a) Preparation procedure of MCH NPs and (b) schematic illustration of MCH NPs for PAI-guided chemo-/photothermal combinational tumor therapy. Adapted from the literature [154]

将多巴胺封装到 MOF 骨架中合成 MOF 复合材料, 也是一种将二者优势高效结合的方法. 陈乾旺课题 组 ${ }^{[155]}$ 按照如图 23a 所示的简单的一锅法, 在 $\mathrm{MnCo}$ 孔隙 中原位生长了 $\mathrm{PDA}$, 得到了一种基于 MOFs 的多功能金 属有机骨架杂化纳米凝胶(MCP NPs), 其不仅可以作为 $\mathrm{T} 1$ 加权 MRI 成像的造影剂(图 23b), 还可以增强光热转 换效率(图 23c). 经过进一步 PEG(聚乙二醇)化和靶向修 饰后, 获得的 MCP-PEG-RGD NPs 具有均匀的尺寸分 布、长期的溶液稳定性、高效的光热转化效率和更高的 肿瘤抑制性等独特优势.

王春刚课题组 ${ }^{[156]}$ 制备了一种包含球形 ZIF-8 和中 空结构聚多巴胺的复合材料 H-ZIF-8/PDA JNPs. 然后, 利用七-(6-颈基-6-脱氧)- $\beta$-环糊精(CD)修饰 PDA 一侧以 加载疏水性药物, 而带有空腔的 ZIF-8 一侧则用于装载 亲水性药物, 合成的 H-ZIF-8/PDA-CD JNPs 具有显著的 光热转换能力、亲疏水药物共载性及 $\mathrm{pH} / \mathrm{NIR}$ 响应的药
物可控释放能力. 此外, H-ZIF-8/PDA-CD JNPs 还具有 良好的生物相容性，可作为双药化疗和 PTT 协同治疗的 有效纳米平台.

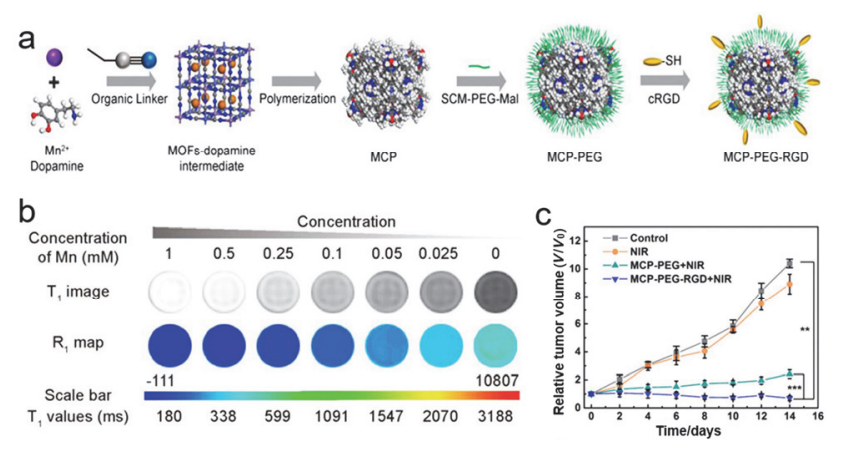

图 23 (a) 制备 MCP, MCP-PEG 和 MCP-PEG-RGD NPs 的示意图; (b) 在不同的锰浓度下, MCP-PEG NPs 的 $\mathrm{T}_{1}$ 加权 MR 图像和 MRI 图像的 $\mathrm{R}_{1}$ 图; (c) 不同处理后小鼠的肿瘤生长曲线 $(n=6)$. 改编自文献[155]

Figure 23 (a) The schematic representation of the preparation of MCP, MCP-PEG, and MCP PEG-RGD NPs; (b) $\mathrm{T}_{1}$-weighted MR images and $\mathrm{R}_{1}$ map of MRI phantom images of MCP-PEG NPs at different Mn concentration; (c) tumor growth curves of mice after different treatments $(n$ $=6)$. Adapted from the literature [155]

聚苯胺具有较强的近红外光的吸收能力和光稳定 性, 但水溶性较差. 将其负载在水溶性较好的纳米载体 上, 进一步调整其形态和大小是一种增强 PAN 分散性 和细胞摄取速率的良好解决办法. 谢志刚课题组 ${ }^{[157]}$ 通 过静电吸附作用合成了具有良好形态的纳米级聚苯胺 MOF 杂化物 UiO-66@PAN. 其具有以下几个潜在的优 点：合适的尺寸、良好的水分散性、强近红外吸收、高 光稳定性及光热转换效率, 在以 PTT 为基础的癌症体内 外治疗中表现出良好的效果.

大多数有机纳米颗粒具有能够生物降解、良好的生 物相容性等优势, 但是有机纳米颗粒特别是有机聚合物 存在着水溶性差等劣势, 极大地限制了其应用范围. $\mathrm{MOF} /$ 有机纳米颗粒的复合物能很好地解决这一问题, 因此，探索一种简单易合成、具有肿瘤细胞靶向性、低 细胞毒性、高药物负载量、具备光热 $/ \mathrm{pH}$ 响应的药物释 放能力及结合多模式成像的 MOF 复合材料将成为研究 人员探索的方向.

\section{MOF 复合材料用于光热杀菌}

目前, 致病性细菌感染已成为威胁公众健康最严重 的问题之一[158-159]. 为了对抗这些感染, 在过去的几十 年里, 人们投入了大量的努力, 开发了各种各样的抗生 素. 然而，长期滥用抗生素，病原体耐药性的增加使得 抗生素的治疗效果大打折扣, 如何实现快速、高效杀菌 而又不会导致细菌抗药性增强已成为当前医疗体系亟 待解决的问题 ${ }^{[160-161]}$. 近年来, 金属纳米粒子[162]、无机 纳米复合材料[163]、带正电的聚合物 ${ }^{[164]}$ 等抗生素的替代 药物已被报道. 其中, MOF 材料因含有大量具有杀菌性 
能的金属离子 (如 $\mathrm{Zn}^{2+} 、 \mathrm{Co}^{2+} 、 \mathrm{Cu}^{2+}$ 和 $\mathrm{Mo}^{6+}$ 等)而被用作 化学抗菌剂[165-169]. 与此同时, 金属离子剂量大、杀菌速 度慢、杀菌效果不理想等缺点也被暴露出来. 为了解决 这些问题, 研究人员已经开发出生物毒性更低、更高效 的杀菌方法一物理破坏策略, 其中光热杀菌和光动力杀 菌已经在临床领域得到了广泛的应用. 金属复合材 料 [95,170]和碳骨架材料 [171-172]在光的激发下可以产生大 量的热和活性氧, 能够实现高效杀菌, 具有巨大的应用 潜力.

高浓度 $\mathrm{Zn}^{2+}$ 对细菌具有抑制作用，其抑菌机制是 扰乱内环境平衡、增强质子对细菌膜的通透性, 从而抑 制细菌的糖酵解、葡萄糖基转移酶的产生和多糖的合 成 ${ }^{[173]}$. 将化学抗菌剂与 PTA 联合使用, 发挥二者的协 同作用以实现更好的抗菌效果是一项引人注目的策略. 吴水林课题组 ${ }^{[174]}$ 通过在聚乙烯吡咯烷酮修饰的腐植酸 (HuA) 表面原位生长 ZIF-8, 合成了纳米复合材料一 HuA@ZIF-8 NP. 在近红外光的照射下, 复合材料中的 $\mathrm{HuA}$ 表现出了高效的光热转换, 并且光热诱导 ZIF-8 解 离可以实现 $\mathrm{Zn}^{2+}$ 的可控释放, 在短时间内对金黄色葡 萄球菌和大肠杆菌表现出良好抗菌效果. 该研究为开发 生物降解性好、成本低、快速有效灭菌的光响应平台提 供了一种很有前景的策略.

MOF 材料碳化后得到的衍生碳材料拥有丰富的金 属原子, 较强的光吸收能力、较高的光热转化效率及较 大的比表面积 ${ }^{[175-176]}$, 为制造具有协同抗菌作用的纳米 剂提供了可能性. 赵长生课题组 ${ }^{[177]}$ 通过对 ZIF-8 进行碳 化及二次氧化, 合成了 $\mathrm{ZnO}$ 掺杂的碳纳米颗粒 $\mathrm{ZnO}$ CNP. 为了获得更好的抗菌效果并最大程度地降低毒 性, 其对 $\mathrm{ZnO} \mathrm{CNP}$ 原位涂覆了热敏凝胶层(TRGL), 制 备了 $\mathrm{ZnO}-\mathrm{CNP}-\mathrm{TRGL}$ 复合材料. 该材料在近红外光的 辐射下, 表现出了较高的光热转换效率和细菌捕获能 力, 其在局域产生的大量热量和大量的 $\mathrm{Zn}^{2+}$ 离子, 可直 接干扰细菌膜和细胞内蛋白的活性. 其课题组成员 ${ }^{[178]}$ 还通过碳化 ZIF-8 前体及 $\mathrm{Ag}^{+}$的后交换处理得到了掺杂 不同含量 $\mathrm{Ag}^{+}$的碳化 ZIF 纳米复合材料 $(\mathrm{C}-\mathrm{Zn} / \mathrm{Ag})$. 该复 合材料具有高效的 $\mathrm{Zn}^{2+} 、 \mathrm{Ag}^{+}$离子释放能力和光热转换 能力, 可以协同破坏细菌膜和细胞内物质以消灭细菌. 上述两种材料的杀菌性能可与万古霉素相媲美.

2019 年, 赵长生课题组 ${ }^{[179]}$ 制备了 MOFs 衍生的石 墨烯上掺杂 $\mathrm{ZnO}$ 的复合材料 $(\mathrm{ZnO} @ \mathrm{G})$, 通过原位聚合 将其与相变热响应材料 (TRB) 结合, 得到功能化的 $\mathrm{TRB}-\mathrm{ZnO} @ \mathrm{G}$ 复合材料(图 24a). 其具有高光热活性及 持续的 $\mathrm{Zn}^{2+}$ 离子释放能力. 如图 $24 \mathrm{~b}$ 所示, 在近红外光 的照射下, 复合材料会形成 TRB-ZnO@G-细菌聚集体, 并且会造成局部大量 $\mathrm{Zn}^{2+}$ 离子的聚集, 实现了光热杀 菌和 $\mathrm{Zn}^{2+}$ 对细菌膜和细胞内物质的协同破坏, 可用于 皮肤伤口快速、安全的杀菌消毒.

吴水林课题组 ${ }^{[180-182]}$ 制备了一系列 MOF 复合材料 来研究光热杀菌和光动力杀菌的协同杀菌能力. 在
2019 年的工作中, 其以普鲁士蓝为核, 以掺杂卟啉的 UiO-66-TCPP 为壳, 合成了具有核 - 壳结构的 $\mathrm{PB} @ \mathrm{MOFs}$ 复合材料(图 25a). 卟啉可以显著加快光激 发电子从 PB 的转移, 抑制电子和空穴的复合, 从而增 强材料的光催化性能. 该复合材料在 $660 \mathrm{~nm}$ 的光照下 能够迅速提高单线态氧的产率, 在 $808 \mathrm{~nm}$ 的近红外光 辐射下, 具有高效的光热转换效率. 如图 $25 \mathrm{~b} 、 25 \mathrm{c}$ 所示, 在 $808+660 \mathrm{~nm}$ 混合光(双光)的照射下，通过光热和光 动力协同作用实现了 $10 \mathrm{~min}$ 内 $99 \%$ 以上的金黄色葡萄 球菌和大肠杆菌的杀灭率 ${ }^{[180]}$.

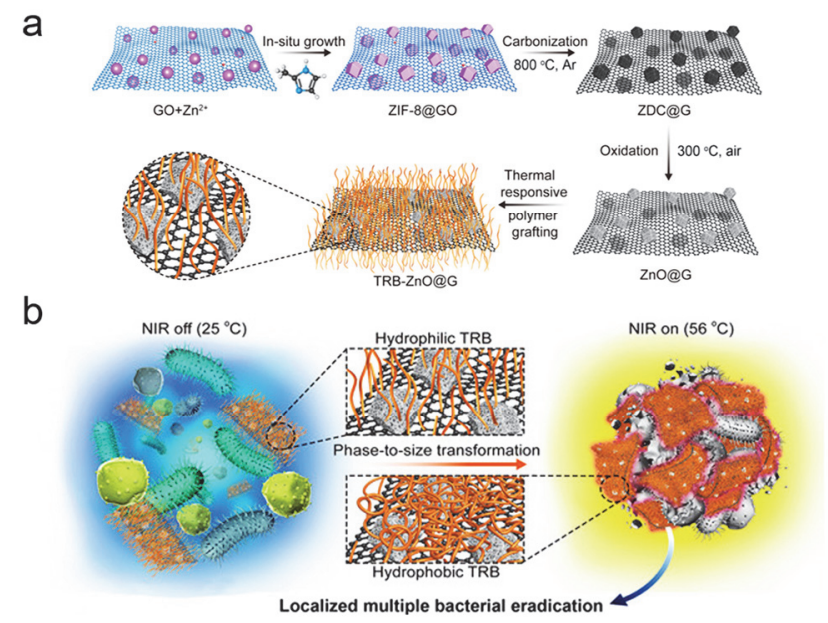

图 24 (a) 制备 2D TRB-ZnO@G 纳米片的示意图; (b) 示意图说明了 NIR 触发的 TRB-ZnO@G 的相到尺寸转化, 以及与包裹和杀死的细菌 相应的微米聚集体的形成. 改编自文献[179]

Figure 24 (a) Schematic illustrations for the preparation of $2 \mathrm{D}$ TRB-ZnO@G nanosheets; (b) schematic illustration of the NIR-triggered phase-to-size transformation of TRB-ZnO@G, and the corresponding formation of micrometer-aggregations with wrapped and killed bacteria. Adapted from the literature [179]

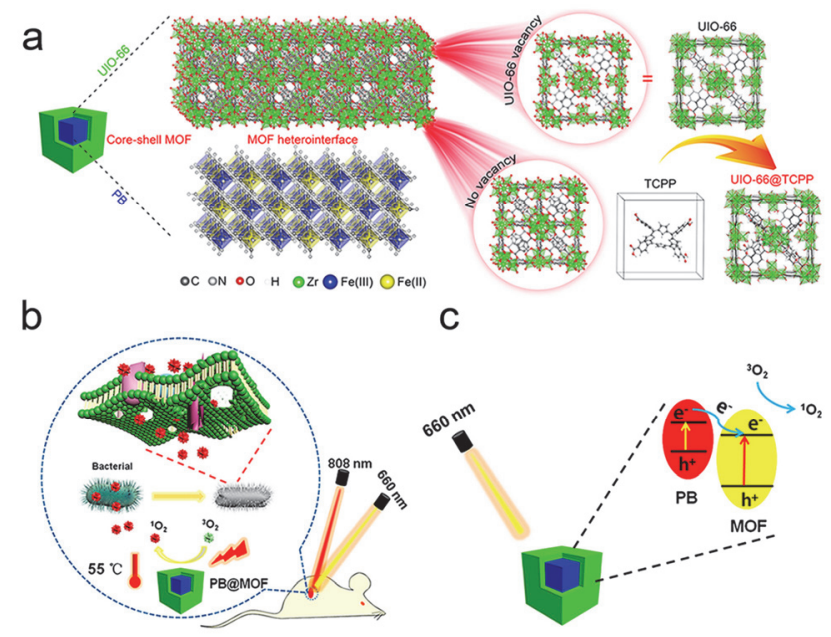

图 25 (a) $\mathrm{PB} @ \mathrm{MOF}$ 的核壳结构示意图; (b) PB@MOF 在双光照射下 杀死细菌的过程示意图; (c) PB@MOF 异质结光催化剂合理的光催化 机理示意图. 改编自文献[180]

Figure 25 (a) Schematic illustration of the core-shell structure of PB@MOF; (b) schematic illustration of the bacteria killing processes with the PB@MOF under dual light irradiation; (c) schematic illustration of rational photocatalytic mechanism for PB@MOF heterojunction photocatalysts. Adapted from the literature [180] 
2020 年, 吴水林课题组成员 ${ }^{[182]}$ 对 HKUST-1 的 $\mathrm{Cu}^{2+}$ 金属节点进行简单的原位硫化处理得到了 CuS@HKUST-1 复合材料. 在复合材料中, HKUST-1 不 仅起到金属前体的作用, 而且能够防止 $\mathrm{CuS}$ 纳米颗粒的 团聚、并释放具有杀菌性能的 $\mathrm{Cu}^{2+}$. CuS 的存在将 MOFs 的光吸收范围拓宽至近红外部分, 在近红外光的照射 下, 复合材料表现出较高的光热转换效率及 ROS 的生 成能力. 实验结果表明, 由于 PTT、PDT 和释放的 $\mathrm{Cu}^{2+}$ 三方面的协同作用，复合材料在 $20 \mathrm{~min}$ 对金黄色葡萄球 菌和大肠杆菌的抗菌效果能够达到 $99.7 \%$ 和 $99.8 \%$ 以上.

由于抗生素的滥用、细菌耐药性的增强, 导致超级 细菌的出现, 严重影响了人类的生命健康. 与肿瘤细胞 的治疗一样, 单一疗法很难实现高效的治疗效果, 化学 抗菌剂与光热、光动力策略的协同杀菌已被越来越多的 研究人员所关注. 因此, 制备能够实现快速、高效的协 同杀菌, 并具有促进创面愈合的材料, 将是人们接下来 的研究重点.

\section{MOF 复合材料用于光热协同催化}

\subsection{MOF 复合材料用于光热化学战剂降解}

尽管《禁止化学武器公约》(CWC) 在国际上禁止化 学武器的使用, 但近年来滥用化学战剂(CWA: 指通过 改变其生理系统杀死或致死的化学药品)的事件数量有 所增加. 因此, 能够安全有效地捕获或降解化学战剂至 关重要 ${ }^{[183-184]}$. 近年来, 具有结晶多孔结构的金属有机 骨架材料成为催化降解化学战剂的研究热点, 其既可以 用作有效的吸附剂, 又可以用作降解 CWA 的非均相催 化剂, 已成为最有希望用于实际降解化学战剂的材料之 - [185-187]. 促进催化降解反应的另一种方法是使用具有 光热效应(PTE)的催化剂[188], 通过将光子转化为热量, 充当催化剂/反应物界面的加热器, 从而促进分子的有 效碰撞和传质 ${ }^{[189-190]}$. PTE 辅助催化具有瞬时升温和局 部加热的优点, 是一种对表面性质要求低、高度可行且 通用的催化策略. 因此, 将具有高效光热转换效率的光 热剂与 MOFs 复合形成功能性的纳米材料, 将有利于 $\mathrm{CWA}$ 的吸附及光热催化降解.

于中振课题组 ${ }^{[25]}$ 在石墨烯纤维上原位生长 UiO-66$\mathrm{NH}_{2}$, 制备了一种新型轻质柔性石墨烯基纳米复合材料 织物( $\mathrm{GF} @ \mathrm{UiO}-66-\mathrm{NH}_{2}$ )(图 26a). 在模拟太阳光的照射 下, 增强了 CWA 模拟物的催化降解效果, 半衰期缩短 至 $1.6 \mathrm{~min}$, 优于其他文献报道的 MOFs 基催化面料. 石 墨烯组分的光热转换效应和从石墨烯到 UiO-66- $\mathrm{NH}_{2}$ 催 化剂的瞬时传热增强了催化活性. 如图 26b 所示, 该材 料在 $5 \mathrm{~min}$ 内实现了 $40{ }^{\circ} \mathrm{C}$ 的升温, 并且随光功率密度 的增强, 复合材料表现出高光热催化降解效率以及良好 的循环稳定性, 具有用于催化降解膦酸酯类剧毒神经毒 剂的应用前景.

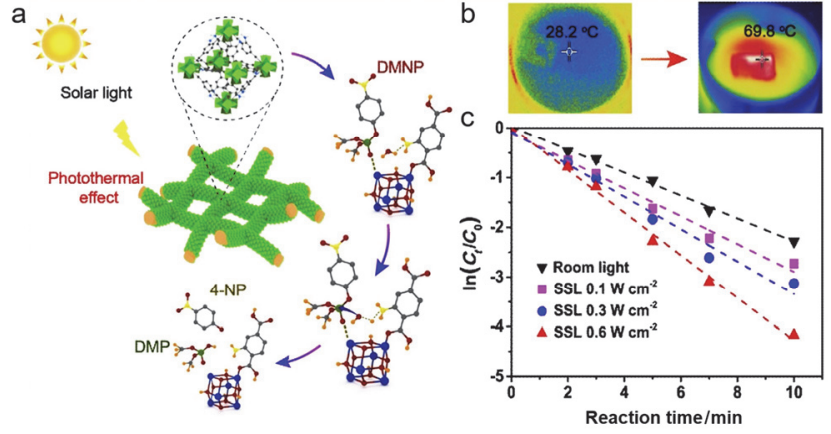

图 26 (a) GF@UiO-66- $\mathrm{NH}_{2}$ 水解 DMNP 的反应机理; (b) 在模拟太阳 光 $\left(0.6 \mathrm{~W} \cdot \mathrm{cm}^{-2}\right)$ 下, $\mathrm{GF} @ \mathrm{UiO}-66-\mathrm{NH}_{2}$ 在干燥状态及水悬浮液中红外照 片; (c) GF@UiO-66- $\mathrm{NH}_{2}$ 存在下不同光照射下 DMNP 的水解动力学线 性拟合曲线. 改编自文献[25]

Figure 26 (a) Proposed reaction mechanism for the hydrolysis of DMNP by GF@UiO-66- $\mathrm{NH}_{2}$; (b) infrared photograph of GF@UiO-66- $\mathrm{NH}_{2}$ in dry state and in its aqueous suspension under the simulated solar light $\left(0.6 \mathrm{~W} \cdot \mathrm{cm}^{-2}\right)$; (c) hydrolysis kinetic linear fitting curves of DMNP in the presence of GF@UiO-66- $\mathrm{NH}_{2}$ under different light irradiations. Adapted from the literature [25]

为了获得具有新型光热增强催化性能的自解毒气 体过滤器, 李澄课题组 ${ }^{[24]}$ 在聚多巴胺纳米颗粒上生长 了 $\mathrm{NH}_{2}$-UiO-66, 合成了如图 27 所示的具有核-壳结构的 Dpa@UiO-66- $\mathrm{NH}_{2}$ CSNs. 在 NIR 光或模拟太阳光的照 射下, 利用聚多巴胺出色的光热效应, 实现了向催化层 的瞬间传热. 此外, 催化剂与反应物间的高接触界面, 使复合材料表现出对化学战剂模拟剂 4-硝基苯基磷酸 二甲酯(DMNP)高效的催化降解效率，通过静电纺丝可 以将 Dpa@UiO-66- $\mathrm{NH}_{2} \mathrm{CSNs}$ 进一步整合到聚合纤维中.

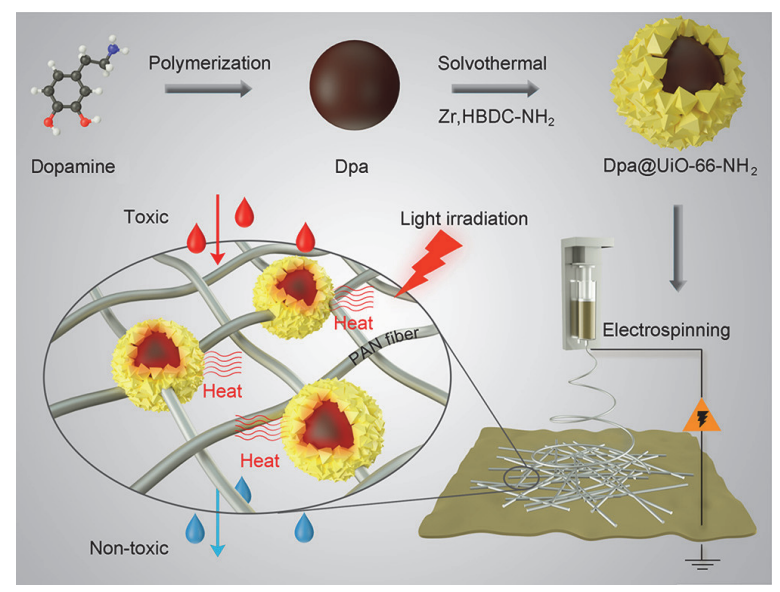

图 $27 \mathrm{Dpa} @ \mathrm{UiO}-66-\mathrm{NH}_{2} \mathrm{CSNs}$ 及其织物用于 $\mathrm{CWA}$ 模拟物光热增强 解毒的制作过程示意图. 改编自文献[24]

Figure 27 Schematic illustration of the fabrication procedures for Dpa@UiO-66- $\mathrm{NH}_{2}$ CSNs and their fabrics for photothermally enhanced detoxification of CWA simulants. Adapted from the literature [24]

如图 28a 所示，该方法可以实现纤维材料的大面积 制备, 并表现出一定的机械稳定性. 如图 28b 所示, 在 NIR 激光照射下, Dpa@UiO-66- $\mathrm{NH}_{2}$ CSNs 的织物表现出 比纯 UiO-66- $\mathrm{NH}_{2}$ 粉末更快的 DMNP 降解速率, 这种新 型的光热强化催化降解 DMNP 的策略可以推广到其他 
催化战剂降解体系中, 给 CWA 净化技术和下一代防毒 面具带来了希望.
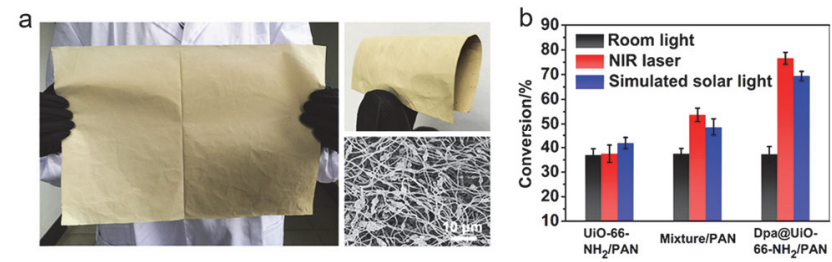

图 28 (a) 照片显示了具有较大面积的独立柔性 UiO-66- $\mathrm{NH}_{2} / \mathrm{PAN}$ 纤 维毡及其相应的 SEM 图像; (b) 在不同的光照条件下, 在过滤器测试 中使用 UiO-66- $\mathrm{NH}_{2} / \mathrm{PAN}$, 混合物/PAN 和 Dpa@UiO-66- $\mathrm{NH}_{2} / \mathrm{PAN}$ 纤 维毡, 将 DMNP 转化为对硝基苯氧化物的百分比. 误差条是三倍读数 的标准偏差. 改编自文献[24]

Figure 28 (a) Photographs showing a stand-alone flexible UiO-66- $\mathrm{NH}_{2} / \mathrm{PAN}$ fibrous mat with a large area and its corresponding SEM image; (b) percentage conversion of DMNP to $p$-nitrophenoxide using UiO-66- $\mathrm{NH}_{2} / \mathrm{PAN}$, mixture/PAN, and Dpa@UiO-66-NH/PAN fibrous mats in the filter test under different light irradiation conditions. Error bars are the standard deviation in triplicate readings. Adapted from the literature [24]

在由纳米级颗粒组成的纤维上形成连续、均匀的 MOFs 薄膜涂层, 同时实现催化剂高负载量和附着力, 有利于提升其催化性能. 2020 年, 李澄课题组 ${ }^{[26]}$ 在具有 良好过滤性能的聚酰胺(PA-6)纳米纤维表面自聚合了一 层聚多巴胺, 通过溶剂热反应原位生长了 $\mathrm{NH}_{2}$-UiO-66, 得到了如图 29 所示的 PA-6@PDA@UiO-66- $\mathrm{NH}_{2}$ 纳米纤 维. 在模拟太阳光照射下, 表现出对化学战剂模拟物 DMNP 高效的降解速率, 其降解半衰期仅为 $0.5 \mathrm{~min}$, 比 迄今为止报道的 $\mathrm{NH}_{2}-\mathrm{UiO}-66$ 粉末和 $\mathrm{NH}_{2}-\mathrm{UiO}-66$ 纤维 复合材料都高. 此合成方法也适用于其他 $\mathrm{MOFs} /$ 纤维 复合材料的制备, 为光热催化降解 CWA 的自解毒织物 的制备提供了新的策略.

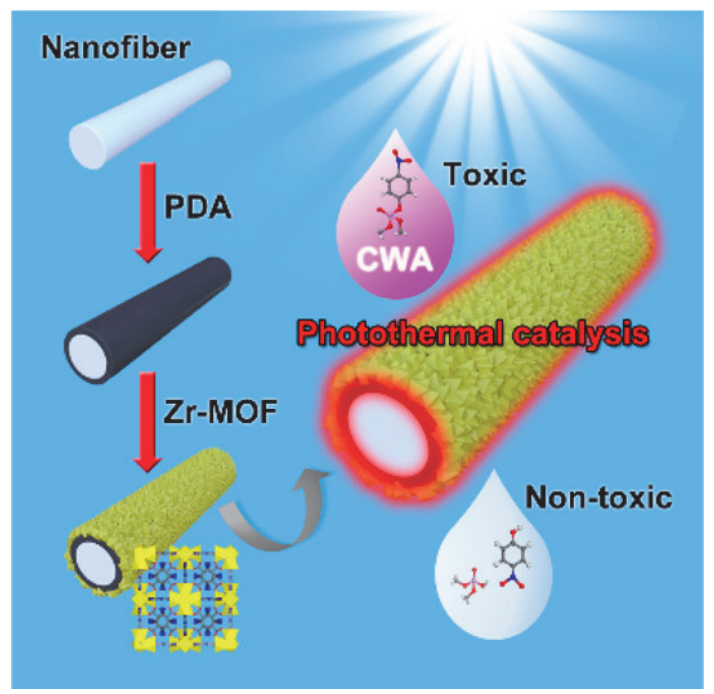

图 $29 \mathrm{PDA}$ 介导的 MOF 织物的制备步骤: 将 PDA 涂覆在静电纺丝 的 PA-6 纳米纤维上, 然后进行多巴胺聚合和 $\mathrm{Zr}-\mathrm{MOF}$ UiO-66- $\mathrm{NH}_{2}$ 在 PA-6@PDA 纳米纤维上的溶剂热生长. 改编自文献[26]

Figure 29 Steps for the preparation of PDA-mediated MOF fabrics: PDA coating on electrospun PA-6 nanofibers by dopamine polymerization and solvothermal growth of $\mathrm{Zr}-\mathrm{MOF}$ UiO-66- $\mathrm{NH}_{2}$ on PA-6@PDA nanofibers. Adapted from the literature [26]
如何实现个人防护以及短时间内的化学战剂降解 仍将是我们所面临的巨大挑战. 目前，虽然 MOF 材料 在水中已经能实现半衰期小于 $1 \mathrm{~min}$ 的快速战剂降解, 并且光热作用可在一定程度上加速化学战剂的降解, 但 是如何制备 MOFs 牢固负载、催化降解性能高且具有柔 性的自解毒织物, 以实现高效的个人防护仍然值得研究 人员进一步探索.

\section{$5.2 \mathrm{MOF}$ 复合材料用于光热催化有机反应}

利用金属纳米晶体的表面等离子体特性，可以实现 太阳能向热能的高效转换. 研究者通过将金属纳米晶体 可控地集成到 MOF 材料中, 实现了二者优势最大化. 在实现高效光热催化的同时, 加快反应底物、产物的传 输, 为实现绿色化学的目标开发了一种新的策

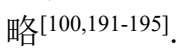

江海龙课题组 ${ }^{[100]}$ 首次尝试将金属纳米颗粒的光热 效应与 MOFs 特性相结合, 以加速催化反应, 开辟了光 热太阳能转换促进催化反应的新途径. 其通过模板合成 法，制备了具有核壳结构的Pd NCs@ZIF-8 复合材料(图 30a). Pd NCs 表面等离子体激元效应, 可以促进光辐照 下的吸热反应; 多孔 MOF 结构可以防止 Pd NCs 的聚集, 并且其孔结构清晰，可以篮分不同大小的分子. 与此同 时，壳体的孔隙结构有利于底物/产物运输到 Pd 的活性 位点，并使 $\mathrm{H}_{2}$ 富集，以提高催化效率. Pd NCs@ZIF-8 实 现了 1-已烯的选择性催化反应(图 30b、30c), 并表现出 良好的循环性.

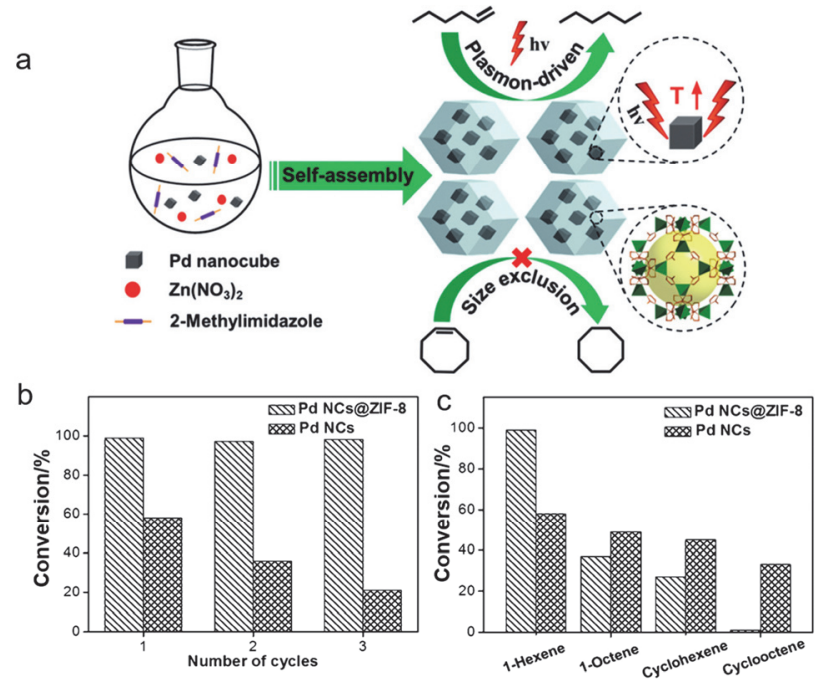

图 30 (a) Pd NCs@ZIF-8 的自组装和等离子体激元驱动的烯烃加氢 选择性催化; (b) Pd NCs@ZIF-8 和 Pd NCs 对 1-已烯氢化的可回收性; (c) 在 Pd NCs@ZIF-8 和 Pd NCs 上各种烯烃的氢化转化. (b)和(c)中的 反应条件: 室温下 $100 \mathrm{~mW} \cdot \mathrm{cm}^{-2}$ 全光谱辐射. 改编自文献[100]

Figure 30 (a) Self-assembly of Pd NCs@ZIF-8 and plasmon-driven selective catalysis of the hydrogenation of olefins; (b) recyclability of Pd NCs@ZIF-8 and Pd NCs for the hydrogenation of 1-hexene; (c) conversions of the hydrogenation of various alkenes over Pd NCs@ZIF-8 and Pd NCs. Reaction conditions in (b) and (c): $100 \mathrm{~mW} \cdot \mathrm{cm}^{-2}$ full-spectrum irradiation, room temperature. Adapted from the literature [100] 
江 海 龙及其合 作 者 ${ }^{[195]}$ 设 计和合成了 Pt/PCN-224(M)复合材料(图 31). 利用 MOF 复合材料的 光热协同作用, 实现了从芳醇到相应醛产物的高效选择 性氧化, 并将催化性能的提升归因于: (1)肖特基结和等 离子体激元效应实现了复合材料对可见光捕集能力的 调整, 增强了复合材料的光热效应, 从而促进了氧化反 应; (2)在可见光的照射下, Pt/PCN-224(Zn) 利用各组分 的协同作用, 实现了 $\mathrm{O}_{2}$ 向 ${ }^{1} \mathrm{O}_{2}$ 的高效转化, 并进一步促 进伯醇高效选择性氧化为相应醛产物.

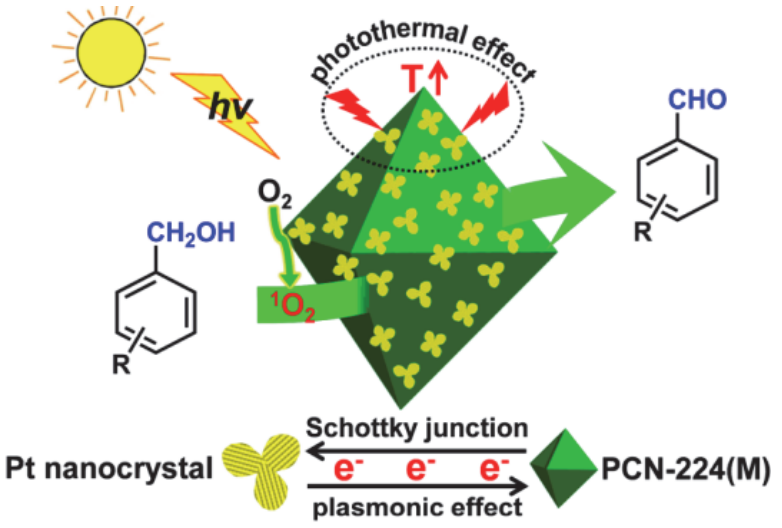

图 31 在可见光照射下, Pt/PCN-224(M)醇的选择性氧化示意图. 改 编自文献[195]

Figure 31 Schematic illustration showing the selective oxidation of alcohols over Pt/PCN-224(M) under visible-light irradiation. Adapted from the literature [195]

金属纳米晶体/MOF 复合材料能够将光转换为化学 反应所需要的热量以促进化学反应的高效进行, 符合绿 色化学的要求. 此外, 一些复合材料在光照下可以产生 单线态氧等活性氧组分, 能够实现高效的协同催化. 目 前对这一领域的研究较少, MOFs 及功能材料的选择、可 控复合及化学反应体系的拓展等方面都存在着广阔的 发展空间.

\section{6 总结与展望}

近年来, 许多研究人员通过溶液浸渍、沉积、固相 研磨以及模板合成等方法制备了多种 MOF 基复合材料. 在利用 MOF 材料的高比表面积、高孔隙率实现特定粒 径的功能材料在 MOFs 上的有效负载和均匀分布的基础 上, 复合材料还可以使功能纳米颗粒的优势(如较宽的 光吸收范围、高光热转换性能、能够作为体内成像的造 影剂等)与 MOFs 自身功能相结合, 通过光热效应加快 分子运动, 从而促进反应底物与催化位点的接触, 并最 终实现多功能协同效应.

MOF 复合材料已广泛应用于光热应用领域, 并且 仍处于高速发展阶段, 但该研究还面临着一些挑战: (1) 用于光热领域的 MOF 材料以 Zr-MOFs、ZIF 系列及 MIL 系列为主, 但这仅占 MOF 材料中的一小部分, 开发适 用于多种孔道结构以及不同稳定性 MOFs 的简便可控的
复合策略和方法具有重要意义; (2) MOFs 与光热纳米材 料简便合成方法、光热协同机制, 特别是从热力学上理 解光热转换的过程和微观粒子相互间的作用力等仍有 待于进一步深入; (3)从微观反应动力学及动态学的基础 上, 通过理论计算研究分子中的电子在能级间的跃迁过 程等, 对于光热转换材料的设计将具有重要意义; (4)对 于 MOFs 与功能纳米材料结构的表征, 目前常用的如 $\mathrm{N}_{2}$ 吸附、TEM 等测试手段，只能辅助证明二者的位置关系， 因此，探索更加精确的表征手段将有利于深入理解各材 料间的构效关系; (5)通过金属的选择、配体的合理设计 (如增强配体的共轭程度以增强光吸收特性)开发具有本 征光热转换性能的 MOF 材料也值得研究人员进一步探 索. 在此基础上, 进行与功能材料的可控结合, 有望得 到具有高效光热转换性能以及附加功能的 MOF 复合材 料.

\section{作者简介}

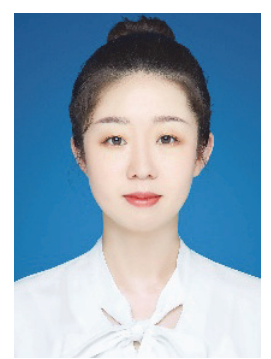

郭彩霞, 北京理工大学硕士研究生. 2018 年本科毕业于山 东师范大学, 现于北京理工大学攻读硕士学位. 主要研究领 域为 MOF 复合材料的制备及光催化性能.

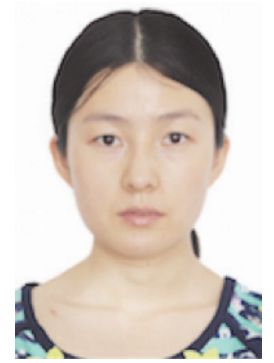

马小杰, 北京理工大学化学与化工学院预聘助理教授, 于兰州大学化学与化工学院取得本科与硕士学位, 中科院化 学研究所获得博士学位. 主要从事多孔材料的环境催化研究 工作.

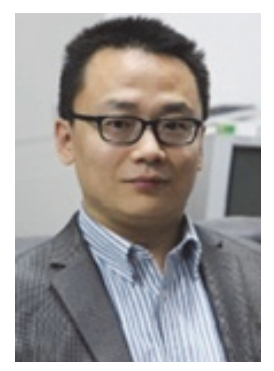

王博, 北京理工大学化学与化工学院教授, 2004 年于北京 大学化学与分子工程学院获理学学士学位, 2006 年于美国密 
歇根大学获化学材料学硕士学位, 2008 年于美国加州大学洛 杉矶分校获化学材料学博士学位. 王博教授主要从事新型纳 米多孔材料、开放框架聚合物理论与设计及其在关键分离过 程、环境防护等领域的应用研究.

\section{References}

[1] Tranchemontagne, D. J.; Mendoza-Cortes, J. L.; O'Keeffe, M.; Yaghi, O. M. Chem. Soc. Rev. 2009, 38, 1257.

[2] Xu, W.; Tu, B.; Liu, Q.; Shu, Y.; Liang, C.-C.; Diercks, C. S.; Yaghi, O. M.; Zhang, Y.-B.; Deng, H.; Li, Q. Nat. Rev. Mater. 2020, 5, 764.

[3] Ma, R.; Jiang, H.; Wang, C.; Zhao, C.; Deng, H. Chem. Commun. (Camb) 2020, 56, 2715.

[4] Wu, Y.; Huang, Z.; Jiang, H.; Wang, C.; Zhou, Y.; Shen, W.; Xu, H.; Deng, H. ACS Appl. Mater. Interfaces 2019, 11, 44573.

[5] Jiang, H.; Jin, S.; Wang, C.; Ma, R.; Song, Y.; Gao, M.; Liu, X.; Shen, A.; Cheng, G. J.; Deng, H. J. Am. Chem. Soc. 2019, 141, 5481.

[6] Jiang, H.; Tong, L.; Liu, H.; Xu, J.; Jin, S.; Wang, C.; Hu, X.; Ye, L.; Deng, H.; Cheng, G. J. Matter 2020, 2, 1535.

[7] Farha, O. K.; Yazaydin, A. O.; Eryazici, I.; Malliakas, C. D.; Hauser, B. G.; Kanatzidis, M. G.; Nguyen, S. T.; Snurr, R. Q.; Hupp, J. T. Nat. Chem. 2010, 2, 944

[8] Inukai, M.; Tamura, M.; Horike, S.; Higuchi, M.; Kitagawa, S.; Nakamura, K. Angew. Chem. Int. Ed. 2018, 57, 8687.

[9] Rosi, N. L.; Eckert, J.; Eddaoudi, M.; Vodak, D. T.; Kim, J.; O'Keeffe, M.; Yaghi, O. M. Science 2003, 300, 1127.

[10] Guo, Z.; Zhang, Y.; Feng, X. Acta Chim. Sinica 2020, 78, 397 (in Chinese). (郭振涁, 张媛媛, 冯霄, 化学学报, 2020, 78, 397.)

[11] Zhang, J.; Li, P.; Zhang, X.; Ma, X.; Wang, B. Acta Chim. Sinica 2020, 78, 597 (in Chinese). (张晋维, 李平, 张馨凝, 马小杰, 王 博, 化学学报, 2020, 78, 597.)

[12] Zhao, M.; Yuan, K.; Wang, Y.; Li, G.; Guo, J.; Gu, L.; Hu, W.; Zhao, H.; Tang, Z. Nature 2016, 539, 76.

[13] Huang, N.; Drake, H.; Li, J.; Pang, J.; Wang, Y.; Yuan, S.; Wang, Q.; Cai, P.; Qin, J.; Zhou, H. C. Angew. Chem. Int. Ed. 2018, 57, 8916.

[14] Xin, Z.; Wang, Y.-R.; Chen, Y.; Li, W.-L.; Dong, L.-Z.; Lan, Y.-Q. Nano Energy 2020, 67, 104233.

[15] Gao, J.; Huang, Q.; Wu, Y.; Lan, Y.-Q.; Chen, B. Adv. Energy Sustainability Res. 2021, 2, 2100033.

[16] Li, X.; Wang, J.; Xue, F.; Wu, Y.; Xu, H.; Yi, T.; Li, Q. Angew. Chem. Int. Ed. 2021, 60, 2534.

[17] Tao, W.; Zhu, X.; Yu, X.; Zeng, X.; Xiao, Q.; Zhang, X.; Ji, X.; Wang, X.; Shi, J.; Zhang, H.; Mei, L. Adv. Mater. 2017, 29, 1603276.

[18] Yang, T.; Cui, Y.; Chen, H.; Li, W. Acta Chim. Sinica 2017, 75, 339 (in Chinese). (杨涛, 崔亚男, 陈怀银, 李伟华, 化学学报, 2017, $75,339$.

[19] Wang, B.; Wang, P.; Xie, L. H.; Lin, R. B.; Lv, J.; Li, J. R.; Chen, B. Nat. Commun. 2019, 10, 3861.

[20] Luo, Y. H.; Xie, A. D.; Hu, M. G.; Wu, J.; Zhang, D. E.; Lan, Y. Q. Inorg. Chem. 2021, 60, 167.

[21] Horcajada, P.; Gref, R.; Baati, T.; Allan, P. K.; Maurin, G.; Couvreur, P.; Ferey, G.; Morris, R. E.; Serre, C. Chem. Rev. 2012, 112, 1232.

[22] Horcajada, P.; Chalati, T.; Serre, C.; Gillet, B.; Sebrie, C.; Baati, T.; Eubank, J. F.; Heurtaux, D.; Clayette, P.; Kreuz, C.; Chang, J. S.; Hwang, Y. K.; Marsaud, V.; Bories, P. N.; Cynober, L.; Gil, S.; Ferey, G.; Couvreur, P.; Gref, R. Nat. Mater. 2010, 9, 172.

[23] Zhang, Y.; Wang, F. M.; Ju, E. G.; Liu, Z.; Chen, Z. W.; Ren, J. S.; $\mathrm{Qu}, \mathrm{X} . \mathrm{G}$. Adv. Funct. Mater. 2016, $26,6454$.

[24] Yao, A.; Jiao, X.; Chen, D.; Li, C. ACS Appl. Mater. Interfaces 2019, $11,7927$.

[25] Song, L.; Zhao, T.; Yang, D.; Wang, X.; Hao, X.; Liu, Y.; Zhang, S.; Yu, Z.-Z. J. Hazard. Mater. 2020, 393, 122332.

[26] Yao, A.; Jiao, X.; Chen, D.; Li, C. ACS Appl. Mater. Interfaces 2020, $12,18437$.

[27] Chen, Y.-J.; Chen, Y.; Miao, C.; Wang, Y.-R.; Gao, G.-K.; Yang, R.-X.; Zhu, H.-J.; Wang, J.-H.; Li, S.-L.; Lan, Y.-Q. J. Mater. Chem. $A$ 2020, 8,14644 .

[28] Wang, P. L.; Xie, L. H.; Joseph, E. A.; Li, J. R.; Su, X. O.; Zhou, H. C. Chem. Rev. 2019, 119, 10638.

[29] Zeng, J.; Wang, X.; Zhang, X.; Zhuo, R. Acta Chim. Sinica 2019, 77, 1156 (in Chinese). (曾锦跃, 王小双, 张先正, 卓仁禧, 化学学报, 2019, 77, 1156.)

[30] Qi, Y.; Ren, S.; Che, Y.; Ye, J.; Ning, G. Acta Chimica Sinica 2020,
78, 613 (in Chinese). (齐野, 任先颂, 车颖, 叶俊伟, 宁桂玲, 化 学学报, 2020, 78, 613.).

[31] Meilikhov, M.; Yusenko, K.; Esken, D.; Turner, S.; Van Tendeloo, G.; Fischer, R. A. Eur. J. Org. Chem. 2010, 3701

[32] Yang, D.; Yang, G.; Gai, S.; He, F.; An, G.; Dai, Y.; Lv, R.; Yang, P. Nanoscale 2015, 7, 19568.

[33] Tian, Q.; Tang, M.; Sun, Y.; Zou, R.; Chen, Z.; Zhu, M.; Yang, S.; Wang, J.; Wang, J.; Hu, J. Adv. Mater. 2011, 23, 3542.

[34] Yang, S. J.; Choi, J. Y.; Chae, H. K.; Cho, J. H.; Nahm, K. S.; Park, C. R. Chem. Mater. 2009, 21, 1893.

[35] Petit, C.; Bandosz, T. J. Adv. Funct. Mater. 2011, 21, 2108.

[36] Prasanth, K. P.; Rallapalli, P.; Raj, M. C.; Bajaj, H. C.; Jasra, R. V. Int. J. Hydrog. Energy 2011, 36, 7594.

[37] Distefano, G.; Suzuki, H.; Tsujimoto, M.; Isoda, S.; Bracco, S.; Comotti, A.; Sozzani, P.; Uemura, T.; Kitagawa, S. Nat. Chem. 2013, 5,335 .

[38] Zhu, Y.-D.; Chen, S.-P.; Zhao, H.; Yang, Y.; Chen, X.-Q.; Sun, J.; Fan, H.-S.; Zhang, X.-D. ACS Appl. Mater. Interfaces 2016, 8, 34209.

[39] Lu, G.; Li, S.; Guo, Z.; Farha, O. K.; Hauser, B. G.; Qi, X.; Wang, Y.; Wang, X.; Han, S.; Liu, X.; DuChene, J. S.; Zhang, H.; Zhang, Q.; Chen, X.; Ma, J.; Loo, S. C.; Wei, W. D.; Yang, Y.; Hupp, J. T.; Huo, F. Nat. Chem. 2012, 4, 310.

[40] Zhu, Q. L.; Xu, Q. Chem. Soc. Rev. 2014, 43, 5468.

[41] Sabo, M.; Henschel, A.; Fröde, H.; Klemm, E.; Kaskel, S. J. Mater. Chem. 2007, 17, 3827.

[42] Khajavi, H.; Stil, H. A.; Kuipers, H. P. C. E.; Gascon, J.; Kapteijn, F. ACS Catal. 2013, 3, 2617.

[43] Guo, Z.; Xiao, C.; Maligal-Ganesh, R. V.; Zhou, L.; Goh, T. W.; Li, X.; Tesfagaber, D.; Thiel, A.; Huang, W. ACS Catal. 2014, 4, 1340.

[44] Volosskiy, B.; Niwa, K.; Chen, Y.; Zhao, Z.; Weiss, N. O.; Zhong, X.; Ding, M.; Lee, C.; Huang, Y.; Duan, X. ACS Nano 2015, 9, 3044.

[45] Jiang, H. L.; Akita, T.; Ishida, T.; Haruta, M.; Xu, Q. J. Am. Chem. Soc. 2011, 133, 1304.

[46] Cao, N.; Yang, L.; Dai, H.; Liu, T.; Su, J.; Wu, X.; Luo, W.; Cheng, G. Inorg. Chem. 2014, 53, 10122.

[47] Shang, N.-Z.; Feng, C.; Gao, S.-T.; Wang, C. Int. J. Hydrog. Energy 2016, $41,944$.

[48] Hwang, Y. K.; Hong, D. Y.; Chang, J. S.; Jhung, S. H.; Seo, Y. K.; Kim, J.; Vimont, A.; Daturi, M.; Serre, C.; Ferey, G. Angew. Chem. Int. Ed. 2008, 47, 4144.

[49] Jiang, Z.; Xu, X.; Ma, Y.; Cho, H. S.; Ding, D.; Wang, C.; Wu, J.; Oleynikov, P.; Jia, M.; Cheng, J.; Zhou, Y.; Terasaki, O.; Peng, T.; Zan, L.; Deng, H. Nature 2020, 586, 549.

[50] Lin, X. Y.; Li, Y. H.; Qi, M. Y.; Tang, Z. R.; Jiang, H. L.; Xu, Y. J. Nanoscale Horiz. 2020, 5, 714.

[51] Yadav, M.; Xu, Q. Chem. Commun. (Camb) 2013, 49, 3327.

[52] Aijaz, A.; Karkamkar, A.; Choi, Y. J.; Tsumori, N.; Ronnebro, E.; Autrey, T.; Shioyama, H.; Xu, Q. J. Am. Chem. Soc. 2012, 134, 13926.

[53] Li, Y. X.; Ji, Y. N.; Jin, M. M.; Qi, S. C.; Li, S. S.; Xue, D. M.; Yue, M. B.; Liu, X. Q.; Sun, L. B. ACS Appl. Mater. Interfaces 2018, 10, 40044.

[54] Zhu, Q. L.; Li, J.; Xu, Q. J. Am. Chem. Soc. 2013, 135, 10210.

[55] Wang, D.; Pan, Y.; Xu, L.; Li, Z. J. Catal. 2018, 361, 248.

[56] Wang, D.; Li, Z. J. Catal. 2016, 342, 151.

[57] Ding, D.; Jiang, Z.; Jin, J.; Li, J.; Ji, D.; Zhang, Y.; Zan, L. J. Catal. 2019, 375, 21.

[58] Meng, X.-B.; Sheng, J.-L.; Tang, H.-L.; Sun, X.-J.; Dong, H.; Zhang, F.-M. Appl. Catal. B 2019, 244, 340.

[59] Hermes, S.; Schroter, M. K.; Schmid, R.; Khodeir, L.; Muhler, M.; Tissler, A.; Fischer, R. W.; Fischer, R. A. Angew. Chem. Int. Ed. 2005, 44, 6237.

[60] Corma, A.; Garcia, H.; Llabres i Xamena, F. X. Chem. Rev. 2010, $110,4606$.

[61] Luz, I.; Rösler, C.; Epp, K.; Llabrés i Xamena, F. X.; Fischer, R. A. Eur. J. Org. Chem. 2015, 2015, 3904.

[62] Proch, S.; Herrmannsdorfer, J.; Kempe, R.; Kern, C.; Jess, A.; Seyfarth, L.; Senker, J. Chemistry 2008, 14, 8204.

[63] Li, P. Z.; Aranishi, K.; Xu, Q. Chem. Commun. (Camb) 2012, 48, 3173.

[64] Lim, D. W.; Yoon, J. W.; Ryu, K. Y.; Suh, M. P. Angew. Chem. Int. Ed. 2012, 51, 9814 .

[65] Hermannsdorfer, J.; Kempe, R. Chemistry 2011, 17, 8071.

[66] Müller, M.; Lebedev, O. I.; Fischer, R. A. J. Mater. Chem. 2008, 18 , 
5274.

[67] George, S. M. Chem. Rev. 2010, 110, 111.

[68] Mondloch, J. E.; Bury, W.; Fairen-Jimenez, D.; Kwon, S.; DeMarco, E. J.; Weston, M. H.; Sarjeant, A. A.; Nguyen, S. T.; Stair, P. C.; Snurr, R. Q.; Farha, O. K.; Hupp, J. T. J. Am. Chem. Soc. 2013, 135, 10294.

[69] Elam, J. W.; Routkevitch, D.; Mardilovich, P. P.; George, S. M. Chem. Mater. 2003, 15, 3507.

[70] Morris, W.; Volosskiy, B.; Demir, S.; Gandara, F.; McGrier, P. L.; Furukawa, H.; Cascio, D.; Stoddart, J. F.; Yaghi, O. M. Inorg. Chem. 2012, 51, 6443.

[71] Klet, R. C.; Wang, T. C.; Fernandez, L. E.; Truhlar, D. G.; Hupp, J. T.; Farha, O. K. Chem. Mater. 2016, 28, 1213.

[72] Peters, A. W.; Li, Z.; Farha, O. K.; Hupp, J. T. ACS Nano 2015, 9 , 8484.

[73] Peters, A. W.; Li, Z.; Farha, O. K.; Hupp, J. T. ACS Appl. Mater. Interfaces 2016, 8, 20675.

[74] Peng, S.; Li, M.; Yang, X.; Li, P.; Liu, H.; Xiong, W.; Peng, X. Ceram. Int. 2019, 45, 18128.

[75] Ahn, S.; Thornburg, N. E.; Li, Z.; Wang, T. C.; Gallington, L. C.; Chapman, K. W.; Notestein, J. M.; Hupp, J. T.; Farha, O. K. Inorg. Chem. 2016, 55, 11954.

[76] Cui, Y.; Rimoldi, M.; Platero-Prats, A. E.; Chapman, K. W.; Hupp, J. T.; Farha, O. K. ChemCatChem 2018, 10, 1772.

[77] Goetjen, T. A.; Zhang, X.; Liu, J.; Hupp, J. T.; Farha, O. K. ACS Sustain. Chem. Eng. 2019, 7, 2553.

[78] Ji, P.; Manna, K.; Lin, Z.; Feng, X.; Urban, A.; Song, Y.; Lin, W. J. Am. Chem. Soc. 2017, 139, 7004.

[79] Ji, P.; Manna, K.; Lin, Z.; Urban, A.; Greene, F. X.; Lan, G.; Lin, W. J. Am. Chem. Soc. 2016, 138, 12234.

[80] Kung, C. W.; Platero-Prats, A. E.; Drout, R. J.; Kang, J.; Wang, T. C.; Audu, C. O.; Hersam, M. C.; Chapman, K. W.; Farha, O. K.; Hupp, J. T. ACS Appl. Mater. Interfaces 2018, 10, 30532.

[81] Li, Z.; Peters, A. W.; Bernales, V.; Ortuno, M. A.; Schweitzer, N. M.; DeStefano, M. R.; Gallington, L. C.; Platero-Prats, A. E.; Chapman, K. W.; Cramer, C. J.; Gagliardi, L.; Hupp, J. T.; Farha, O. K. ACS Cent. Sci. 2017, 3, 31.

[82] Liu, J.; Redfern, L. R.; Liao, Y.; Islamoglu, T.; Atilgan, A.; Farha, O. K.; Hupp, J. T. ACS Appl. Mater. Interfaces 2019, 11, 47822.

[83] Noh, H.; Cui, Y.; Peters, A. W.; Pahls, D. R.; Ortuno, M. A.; Vermeulen, N. A.; Cramer, C. J.; Gagliardi, L.; Hupp, J. T.; Farha, O. K. J. Am. Chem. Soc. 2016, 138, 14720.

[84] Wang, Y.-H.; Chuang, C.-H.; Chiu, T.-A.; Kung, C.-W.; Yu, W.-Y. J. Phys. Chem. C 2020, 124, 12521.

[85] Wang, Y.-S.; Chen, Y.-C.; Li, J.-H.; Kung, C.-W. Eur. J. Org. Chem. 2019, 2019, 3036.

[86] Yuan, S.; Chen, Y. P.; Qin, J.; Lu, W.; Wang, X.; Zhang, Q.; Bosch, M.; Liu, T. F.; Lian, X.; Zhou, H. C. Angew. Chem. Int. Ed. 2015, 54, 14696.

[87] Noh, H.; Kung, C.-W.; Otake, K.-i.; Peters, A. W.; Li, Z.; Liao, Y.; Gong, X.; Farha, O. K.; Hupp, J. T. ACS Catal. 2018, 8, 9848.

[88] Kung, C.-W.; Audu, C. O.; Peters, A. W.; Noh, H.; Farha, O. K.; Hupp, J. T. ACS Energy Lett. 2017, 2, 2394.

[89] He, D.; Niu, H.; He, S.; Mao, L.; Cai, Y.; Liang, Y. Water Res. 2019, $162,151$.

[90] Li, X.; Zhang, Z.; Xiao, W.; Deng, S.; Chen, C.; Zhang, N. J. Mater. Chem. A 2019, 7, 14504.

[91] Bhattacharyya, S.; Rambabu, D.; Maji, T. K. J. Mater. Chem. A 2019, 7, 21106.

[92] Li, Y.; Jin, J.; Wang, D.; Lv, J.; Hou, K.; Liu, Y.; Chen, C.; Tang, Z. Nano Res. 2018, 11, 3294.

[93] He, J.; Dong, J.; Hu, Y.; Li, G.; Hu, Y. Nanoscale 2019, 11, 6089.

[94] Zhu, W.; Chen, M.; Liu, Y.; Tian, Y.; Song, Z.; Song, G.; Zhang, X. Nanoscale 2019, 11, 20630.

[95] Liu, C.; Luo, L.; Zeng, L.; Xing, J.; Xia, Y.; Sun, S.; Zhang, L.; Yu, Z.; Yao, J.; Yu, Z.; Akakuru, O. U.; Saeed, M.; Wu, A. Small 2018, 14, e1801851.

[96] Zhang, H.; Zhang, Q.; Liu, C.; Han, B. Biomater. Sci. 2019, 7, 1696.

[97] Deng, X.; Liang, S.; Cai, X.; Huang, S.; Cheng, Z.; Shi, Y.; Pang, M.; Ma, P. a.; Lin, J. Nano Lett. 2019, 19, 6772.

[98] Zhang, L.; Liu, C.; Gao, Y.; Li, Z.; Xing, J.; Ren, W.; Zhang, L.; Li, A.; Lu, G.; Wu, A.; Zeng, L. Adv. Healthc. Mater. 2018, 7, e1801144.

[99] Fang, L.; Wang, W.; Liu, Y.; Xie, Z.; Chen, L. Dalton Trans. 2017, $46,8933$.

[100] Yang, Q.; Xu, Q.; Yu, S.-H.; Jiang, H.-L. Angew. Chem. Int. Ed.
2016, 55,3685

[101] Wang, L.; Li, S. R.; Chen, Y. Z.; Jiang, H. L. Small 2021, e2004481.

[102] Wu, H.; Gu, D.; Xia, S.; Chen, F.; You, C.; Sun, B. Biomater. Sci. 2021, 9, 1020.

[103] Sui, C.; Tan, R.; Chen, Y.; Yin, G.; Wang, Z.; Xu, W.; Li, X Bioconjug. Chem. 2021, 32, 318.

[104] Park, H.; Yang, J.; Lee, J.; Haam, S.; Choi, I. H.; Yoo, K. H. ACS Nano 2009, 3, 2919.

[105] Zou, L.; Wang, H.; He, B.; Zeng, L.; Tan, T.; Cao, H.; He, X.; Zhang, Z.; Guo, S.; Li, Y. Theranostics 2016, 6, 762.

[106] Zhu, H.; Cheng, P.; Chen, P.; Pu, K. Biomater. Sci. 2018, 6, 746.

[107] Gai, S.; Yang, G.; Yang, P.; He, F.; Lin, J.; Jin, D.; Xing, B. Nano Today 2018, 19, 146.

[108] Gong, H.; Dong, Z.; Liu, Y.; Yin, S.; Cheng, L.; Xi, W.; Xiang, J.; Liu, K.; Li, Y.; Liu, Z. Adv. Funct. Mater. 2014, 24, 6492.

[109] Arvizo, R. R.; Bhattacharyya, S.; Kudgus, R. A.; Giri, K.; Bhattacharya, R.; Mukherjee, P. Chem. Soc. Rev. 2012, 41, 2943.

[110] von Maltzahn, G.; Park, J. H.; Agrawal, A.; Bandaru, N. K.; Das, S. K.; Sailor, M. J.; Bhatia, S. N. Cancer Res. 2009, 69, 3892.

[111] Huang, X.; Tang, S.; Mu, X.; Dai, Y.; Chen, G.; Zhou, Z.; Ruan, F.; Yang, Z.; Zheng, N. Nat. Nanotechnol. 2011, 6, 28.

[112] Guo, T.; Wu, Y.; Lin, Y.; Xu, X.; Lian, H.; Huang, G.; Liu, J. Z.; Wu, X.; Yang, H. H. Small 2018, 14, 1702815.

[113] Lu, J.; Yang, J.; Carvalho, A.; Liu, H.; Lu, Y.; Sow, C. H. Acc. Chem. Res. 2016, 49, 1806.

[114] Liu, J.; Liu, T.; Du, P.; Zhang, L.; Lei, J. Angew. Chem. Int. Ed. 2019, 58, 7808 .

[115] Biswal, B. P.; Shinde, D. B.; Pillai, V. K.; Banerjee, R. Nanoscale 2013, 5, 10556.

[116] Tian, Z.; Yao, X.; Ma, K.; Niu, X.; Grothe, J.; Xu, Q.; Liu, L.; Kaskel, S.; Zhu, Y. ACS Omega 2017, 2, 1249.

[117] Cheng, L.; Yang, K.; Li, Y.; Chen, J.; Wang, C.; Shao, M.; Lee, S. T.; Liu, Z. Angew. Chem. Int. Ed. 2011, 50, 7385.

[118] Li, W.; Wang, J.; Ren, J.; Qu, X. J. Am. Chem. Soc. 2014, 136, 2248.

[119] Cheng, L.; Yang, K.; Li, Y.; Zeng, X.; Shao, M.; Lee, S. T.; Liu, Z. Biomaterials 2012, 33, 2215.

[120] Cheng, Z.; Dai, Y.; Kang, X.; Li, C.; Huang, S.; Lian, H.; Hou, Z.; Ma, P.; Lin, J. Biomaterials 2014, 35, 6359.

[121] Yang, W.; Li, X.; Chi, D.; Zhang, H.; Liu, X. Nanotechnol. 2014, 25, 482001.

[122] Zhou, J.; Liu, Q.; Feng, W.; Sun, Y.; Li, F. Chem. Rev. 2015, 115, 395.

[123] Chen, G.; Qiu, H.; Prasad, P. N.; Chen, X. Chem. Rev. 2014, 114, 5161.

[124] Liu, Q.; Yang, T.; Feng, W.; Li, F. J. Am. Chem. Soc. 2012, 134, 5390.

[125] Gao, S.; Zheng, P.; Li, Z.; Feng, X.; Yan, W.; Chen, S.; Guo, W.; Liu, D.; Yang, X.; Wang, S.; Liang, X. J.; Zhang, J. Biomaterials 2018, 178,83 .

[126] Deng, K.; Hou, Z.; Li, X.; Li, C.; Zhang, Y.; Deng, X.; Cheng, Z.; Lin, J. Sci. Rep. 2015, 5, 7851.

[127] Yang, D.; Xu, J.; Yang, G.; Zhou, Y.; Ji, H.; Bi, H.; Gai, S.; He, F.; Yang, P. Chem. Eng. J. 2018, 344, 363.

[128] Cheng, L.; Gong, H.; Zhu, W.; Liu, J.; Wang, X.; Liu, G.; Liu, Z. Biomaterials 2014, 35, 9844.

[129] Yang, Y.; Jing, L.; Li, X.; Lin, L.; Yue, X.; Dai, Z. Theranostics 2017, 7, 466 .

[130] Wang, D.; Zhou, J.; Chen, R.; Shi, R.; Zhao, G.; Xia, G.; Li, R.; Liu, Z.; Tian, J.; Wang, H.; Guo, Z.; Wang, H.; Chen, Q. Biomaterials 2016, 100, 27.

[131] Valko, M.; Morris, H.; Cronin, M. T. D. Chem. Mater. 2005, 12, 1161

[132] Wang, D.; Zhou, J.; Shi, R.; Wu, H.; Chen, R.; Duan, B.; Xia, G.; Xu, P.; Wang, H.; Zhou, S.; Wang, C.; Wang, H.; Guo, Z.; Chen, Q. Theranostics 2017, 7, 4605.

[133] Dong, W.; Li, Y.; Niu, D.; Ma, Z.; Gu, J.; Chen, Y.; Zhao, W.; Liu, X.; Liu, C.; Shi, J. Adv. Mater. 2011, 23, 5392.

[134] Yang, K.; Hu, L.; Ma, X.; Ye, S.; Cheng, L.; Shi, X.; Li, C.; Li, Y.; Liu, Z. Adv. Mater. 2012, 24, 1868.

[135] Tang, S.; Huang, X.; Zheng, N. Chem. Commun. (Camb) 2011, 47, 3948 .

[136] Liu, Y.; Bai, J.; Jia, X.; Jiang, X.; Guo, Z. ACS Appl. Mater Interfaces 2015, 7, 112.

[137] Liu, H.; Chen, D.; Li, L.; Liu, T.; Tan, L.; Wu, X.; Tang, F. Angew. Chem. Int. Ed. 2011, 50, 891. 
[138] Jin, C. S.; Lovell, J. F.; Chen, J.; Zheng, G. ACS Nano 2013, 7, 2541.

[139] Yang, K.; Xu, H.; Cheng, L.; Sun, C.; Wang, J.; Liu, Z. Adv. Mater. 2012, 24, 5586.

[140] Guo, R.; Peng, H.; Tian, Y.; Shen, S.; Yang, W. Small 2016, 12, 4541.

[141] Wang, Y.; Yang, T.; Ke, H.; Zhu, A.; Wang, Y.; Wang, J.; Shen, J.; Liu, G.; Chen, C.; Zhao, Y.; Chen, H. Adv. Mater. 2015, 27, 3874.

[142] Li, B.; Wang, X.; Chen, L.; Zhou, Y.; Dang, W.; Chang, J.; Wu, C. Theranostics 2018, 8, 4086.

[143] Zheng, X.; Wang, L.; Liu, M.; Lei, P.; Liu, F.; Xie, Z. Chem. Mater. 2018, 30, 6867.

[144] Yang, Y.; Liu, J.; Liang, C.; Feng, L.; Fu, T.; Dong, Z.; Chao, Y.; Li, Y.; Lu, G.; Chen, M.; Liu, Z. ACS Nano 2016, 10, 2774.

[145] Chen, L.; Zhang, J.; Zhou, X.; Yang, S.; Zhang, Q.; Wang, W.; You, Z.; Peng, C.; He, C. Acta Biomater. 2019, 86, 406.

[146] Cai, X.; Liu, B.; Pang, M.; Lin, J. Dalton Trans. 2018, 47, 16329.

[147] Cai, W.; Gao, H.; Chu, C.; Wang, X.; Wang, J.; Zhang, P.; Lin, G.; Li, W.; Liu, G.; Chen, X. ACS Appl. Mater. Interfaces 2017, 9, 2040.

[148] Wang, C.; Xu, H.; Liang, C.; Liu, Y.; Li, Z.; Yang, G.; Cheng, L.; Li, Y.; Liu, Z. ACS Nano 2013, 7, 6782.

[149] Cai, X.; Deng, X.; Xie, Z.; Shi, Y.; Pang, M.; Lin, J. Chem. Eng. J. 2019, 358, 369.

[150] Chen, X.; Zhang, M.; Li, S.; Li, L.; Zhang, L.; Wang, T.; Yu, M.; Mou, Z.; Wang, C. J. Mater. Chem. B 2017, 5, 1772.

[151] Huang, J.; Li, N.; Zhang, C.; Meng, Z. ACS Appl. Mater. Interfaces 2018, 10, 38729.

[152] Repenko, T.; Fokong, S.; De Laporte, L.; Go, D.; Kiessling, F.; Lammers, T.; Kuehne, A. J. Chem. Commun. (Camb) 2015, 51, 6084.

[153] Wu, Q.; Niu, M.; Chen, X.; Tan, L.; Fu, C.; Ren, X.; Ren, J.; Li, L.; $\mathrm{Xu}, \mathrm{K}$.; Zhong, H.; Meng, X. Biomaterials 2018, 162, 132.

[154] Zhang, Y.; Wang, L.; Liu, L.; Lin, L.; Liu, F.; Xie, Z.; Tian, H.; Chen, X. ACS Appl. Mater. Interfaces 2018, 10, 41035.

[155] Wang, D.; Wu, H.; Zhou, J.; Xu, P.; Wang, C.; Shi, R.; Wang, H.; Wang, H.; Guo, Z.; Chen, Q. Adv. Sci. 2018, 5, 1800287.

[156] Li, S.; Zhang, L.; Liang, X.; Wang, T.; Chen, X.; Liu, C.; Li, L.; Wang, C. Chem. Eng. J. 2019, 378, 122175.

[157] Wang, W.; Wang, L.; Li, Y.; Liu, S.; Xie, Z.; Jing, X. Adv. Mater. 2016, 28, 9320.

[158] Varadi, L.; Luo, J. L.; Hibbs, D. E.; Perry, J. D.; Anderson, R. J.; Orenga, S.; Groundwater, P. W. Chem. Soc. Rev. 2017, 46, 4818.

[159] Whiteley, M.; Diggle, S. P.; Greenberg, E. P. Nature 2017, 551, 313.

[160] D'Elia, R. V.; Woods, S.; Butcher, W.; McGahon, J.; Khadke, S.; Perrie, Y.; Williamson, E. D.; Roberts, C. W. J. Control. Release 2019, 298, 202.

[161] Raffatellu, M. Nat. Med. 2018, 24, 1097.

[162] Schlaich, C.; Li, M.; Cheng, C.; Donskyi, I. S.; Yu, L.; Song, G.; Osorio, E.; Wei, Q.; Haag, R. Adv. Mater. Interfaces 2018, 5, 1701254.

[163] Wang, W.; Hao, C.; Sun, M.; Xu, L.; Wu, X.; Xu, C.; Kuang, H. Adv. Funct. Mater. 2018, 28, 1805112.

[164] Joseph, R.; Naugolny, A.; Feldman, M.; Herzog, I. M.; Fridman, M.; Cohen, Y. J. Am. Chem. Soc. 2016, 138, 754.

[165] Zhang, Y.; Sun, P.; Zhang, L.; Wang, Z.; Wang, F.; Dong, K.; Liu, Z.; Ren, J.; Qu, X. Adv. Funct. Mater. 2019, 29, 1808594.

[166] Song, Z.; Wu, Y.; Cao, Q.; Wang, H.; Wang, X.; Han, H. Adv. Funct. Mater. 2018, 28, 1800011.

[167] Nie, X.; Wu, S.; Huang, F.; Wang, Q.; Wei, Q. ACS Appl. Mater. Interfaces 2021, 13, 2245.

[168] Luo, Y.; Liu, X.; Tan, L.; Li, Z.; Yeung, K. W. K.; Zheng, Y.; Cui, Z.; Liang, Y.; Zhu, S.; Li, C.; Wang, X.; Wu, S. Chem. Eng. J. 2021,
$405,126730$.

[169] Liu, J.; Wu, D.; Zhu, N.; Wu, Y.; Li, G. Trend Food Sci. Technol. 2021, 109, 413.

[170] Min, H.; Wang, J.; Qi, Y.; Zhang, Y.; Han, X.; Xu, Y.; Xu, J.; Li, Y.; Chen, L.; Cheng, K.; Liu, G.; Yang, N.; Li, Y.; Nie, G. Adv. Mater. 2019, 31, e1808200.

[171] Yang, Y.; Ma, L.; Cheng, C.; Deng, Y.; Huang, J.; Fan, X.; Nie, C.; Zhao, W.; Zhao, C. Adv. Funct. Mater. 2018, 28, 1705708.

[172] Yu, X.; He, D.; Zhang, X.; Zhang, H.; Song, J.; Shi, D.; Fan, Y.; Luo, G.; Deng, J. ACS Appl. Mater. Interfaces 2019, 11, 1766.

[173] Phan, T. N.; Buckner, T.; Sheng, J.; Baldeck, J. D.; Marquis, R. E. Oral Microbiol. Immun. 2004, 19, 31.

[174] Liu, Z.; Tan, L.; Liu, X.; Liang, Y.; Zheng, Y.; Yeung, K. W. K.; Cui, Z.; Zhu, S.; Li, Z.; Wu, S. Colloids Surf. B 2020, 188, 110781.

[175] Pan, X.; Bai, L.; Wang, H.; Wu, Q.; Wang, H.; Liu, S.; Xu, B.; Shi, X.; Liu, H. Adv. Mater. 2018, 30, e1800180.

[176] Li, S.; Cheng, C.; Sagaltchik, A.; Pachfule, P.; Zhao, C.; Thomas, A. Adv. Funct. Mater. 2019, 29, 1807419

[177] Yang, Y.; Deng, Y.; Huang, J.; Fan, X.; Cheng, C.; Nie, C.; Ma, L.; Zhao, W.; Zhao, C. Adv. Funct. Mater. 2019, 29, 1900143.

[178] Yang, Y.; Wu, X.; He, C.; Huang, J.; Yin, S.; Zhou, M.; Ma, L.; Zhao, W.; Qiu, L.; Cheng, C.; Zhao, C. ACS Appl. Mater. Interfaces 2020, 12, 13698.

[179] Fan, X.; Yang, F.; Huang, J.; Yang, Y.; Nie, C.; Zhao, W.; Ma, L.; Cheng, C.; Zhao, C.; Haag, R. Nano Lett. 2019, 19, 5885.

[180] Luo, Y.; Li, J.; Liu, X.; Tan, L.; Cui, Z.; Feng, X.; Yang, X.; Liang, Y.; Li, Z.; Zhu, S.; Zheng, Y.; Yeung, K. W. K.; Yang, C.; Wang, X.; Wu, S. ACS Cent. Sci. 2019, 5, 1591.

[181] Han, D.; Han, Y.; Li, J.; Liu, X.; Yeung, K. W. K.; Zheng, Y.; Cui, Z.; Yang, X.; Liang, Y.; Li, Z.; Zhu, S.; Yuan, X.; Feng, X.; Yang, C.; Wu, S. Appl. Catal. B 2020, 261, 118248.

[182] Yu, P.; Han, Y.; Han, D.; Liu, X.; Liang, Y.; Li, Z.; Zhu, S.; Wu, S. J. Hazard. Mater. 2020, 390, 122126.

[183] Enserink, M. Science 2013, 341, 1050.

[184] Orcutt, M.; Rayes, D.; Tarakji, A.; Katoub, M.; Spiegel, P.; Rubenstein, L.; Jabbour, S.; Alkhalil, M.; Alabbas, M.; Abbara, A. Lancet 2019, 394, 100.

[185] Bobbitt, N. S.; Mendonca, M. L.; Howarth, A. J.; Islamoglu, T; Hupp, J. T.; Farha, O. K.; Snurr, R. Q. Chem. Soc. Rev. 2017, 46, 3357.

[186] DeCoste, J. B.; Peterson, G. W. Chem. Rev. 2014, 114, 5695.

[187] Liu, Y.; Howarth, A. J.; Vermeulen, N. A.; Moon, S.-Y.; Hupp, J. T.; Farha, O. K. Coord. Chem. Rev. 2017, 346, 101.

[188] Yang, M. Q.; Gao, M.; Hong, M.; Ho, G. W. Adv. Mater. 2018, 30, e1802894.

[189] Meng, X.; Wang, T.; Liu, L.; Ouyang, S.; Li, P.; Hu, H.; Kako, T.; Iwai, H.; Tanaka, A.; Ye, J. Angew. Chem. Int. Ed. 2014, 53, 11478.

[190] Wang, F.; Huang, Y.; Chai, Z.; Zeng, M.; Li, Q.; Wang, Y.; Xu, D. Chem. Sci. 2016, 7, 6887.

[191] Li, L.; Yang, W.; Yang, Q.; Guan, Q.; Lu, J.; Yu, S.-H.; Jiang, H.-L. ACS Catal. 2020, 10, 7753.

[192] Yang, Q.; Yang, C. C.; Lin, C. H.; Jiang, H. L. Angew. Chem. Int. Ed. 2019, 58, 3511.

[193] Wang, S. S.; Jiao, L.; Qian, Y.; Hu, W. C.; Xu, G. Y.; Wang, C.; Jiang, H. L. Angew. Chem. Int. Ed. 2019, 58, 10713.

[194] Xiao, J.-D.; Jiang, H.-L. Acc. Chem. Res. 2018, 52, 356.

[195] Chen, Y.-Z.; Wang, Z. U.; Wang, H.; Lu, J.; Yu, S.-H.; Jiang, H.-L. J. Am. Chem. Soc. 2017, 139, 2035.

(Cheng, B.) 